\title{
Chaotic variability of the meridional overturning circulation on subannual to interannual timescales
}

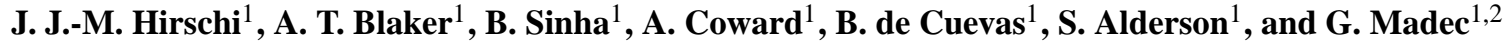 \\ ${ }^{1}$ National Oceanography Centre, Southampton, Southampton, SO14 3ZH, UK \\ ${ }^{2}$ LOCEAN (CNRS/IRD/UPMC/MNHN) Institut Pierre et Simon Laplace, Paris, France
}

Correspondence to: J. J.-M. Hirschi (jjmh@noc.soton.ac.uk)

Received: 2 July 2012 - Published in Ocean Sci. Discuss.: 12 October 2012

Revised: 12 July 2013 - Accepted: 30 July 2013 - Published: 9 September 2013

\begin{abstract}
Observations and numerical simulations have shown that the meridional overturning circulation (MOC) exhibits substantial variability on sub- to interannual timescales. This variability is not fully understood. In particular it is not known what fraction of the MOC variability is caused by processes such as mesoscale ocean eddies and waves which are ubiquitous in the ocean. Here we analyse twin experiments performed with a global ocean model at eddying $\left(1 / 4^{\circ}\right)$ and non-eddying $\left(1^{\circ}\right)$ resolutions. The twin experiments are forced with the same surface fluxes for the 1958 to 2001 period but start from different initial conditions. Our results show that on subannual to interannual timescales a large fraction of MOC variability directly reflects variability in the surface forcing. Nevertheless, in the eddy-permitting case there is an initial-condition-dependent MOC variability (hereinafter referred to as "chaotic" variability) of several $\mathrm{Sv}\left(1 \mathrm{~Sv}=10^{6} \mathrm{~m}^{3} \mathrm{~s}^{-1}\right)$ in the Atlantic and the Indo-Pacific. In the Atlantic the chaotic MOC variability represents up to $30 \%$ of the total variability at the depths where the maximum MOC occurs. In comparison the chaotic MOC variability is only $5-10 \%$ in the non-eddying case. The surface forcing being almost identical in the twin experiments suggests that mesoscale ocean eddies are the most likely cause for the increased chaotic MOC variability in the eddying case. The exact formation time of eddies is determined by the initial conditions which are different in the two model passes, and as a consequence the mesoscale eddy field is decorrelated in the twin experiments. In regions where eddy activity is high in the eddy-permitting model, the correlation of sea surface height variability in the twin runs is close to zero. In the non-eddying case in contrast, we find high correlations ( 0.9 or higher) over most regions. Looking
\end{abstract}

at the sub- and interannual MOC components separately reveals that most of the chaotic MOC variability is found on subannual timescales for the eddy-permitting model. On interannual timescales the amplitude of the chaotic MOC variability is much smaller and the amplitudes are comparable for both the eddy-permitting and non-eddy-permitting model resolutions. Whereas the chaotic MOC variability on interannual timescales only accounts for a small fraction of the total chaotic MOC variability in the eddy-permitting case, it is the main contributor to the chaotic variability in the non-eddying case away from the Equator.

\section{Introduction}

Climate variability consists of both predictable and unpredictable (chaotic) components where there is no predictability beyond a decorrelation time. Examples of predictable variability in the climate system are the diurnal cycle occurring as the Earth spins around its axis or the seasonal cycle, which is a consequence of the inclination of the Earth's axis with respect to the ecliptic. Seasonal changes in temperature, precipitation and wind give rise to the known sequence of the seasons which shape the climate of the different regions of the globe. An example of predictable variability on much longer timescales is the timing of the multimillennial ice age cycles which have characterised the Earth's climate for the last $2 \mathrm{Ma}$. The timing of the ice age cycles are given by changes in radiative forcing due to periodically changing parameters in the Earth's orbit around the Sun (Imbrie et al., 1992; Bradley, 1985). Finally, another prominent example of climatic variability that also contains predictability on 
longer timescales (multi-decadal or longer) are the climate changes occurring in response to the emission of anthropogenic greenhouse gases into the atmosphere. Even though the debate about the amplitude of these changes and about their regional imprint is still ongoing, the basic physical mechanisms responsible for the greenhouse effect are well understood, which makes global climate change likely to be at least partly predictable.

In the examples of natural predictable climate variability given above the forcing is external (variations in insolation). However, despite the high predictability of this external forcing, the diurnal, seasonal and ice age cycles are also modulated by the internal variability of the climate system. The amplitude of the diurnal cycle for example depends on the weather. Similarly, seasons are affected by the prevailing state of the atmospheric circulation and, despite the external forcing (insolation) typically being very similar from year to year, there is a large variability when the same season is compared between different years; e.g. at a given location a cold and dry winter in one year may be followed by a mild and wet one the following year.

The daily weather is probably the best known example of internal, unpredictable (chaotic) variability in the climate system. Even with the increasing wealth of observations available to define the initial conditions and constrain solutions in forecasting models, skilful forecasts are typically not possible for periods of more than 10 days and the reliability of forecasts rapidly drops after a few days. Events such as the onset and termination of blocking events in the atmosphere (linked to prolonged cold/warm, wet/dry conditions) are also largely unpredictable on timescales longer than a few days. In some instances there can be some early warning signs that a mode of variability could be in a certain state in a coming season (e.g. the North Atlantic Oscillation (NAO); Czaja and Frankignoul, 2002), but nevertheless, reliable seasonal forecasts tend to be elusive for many parts of the globe. Successful seasonal forecasts can be made for the El Niño Southern Oscillation (ENSO) which tends to occur every 2 to $7 \mathrm{yr}$. Changes in tropical Pacific subsurface ocean temperature observed by the TOGA-TAO system can detect a coming El Niño event up to six months in advance (McPhaden, 1999). However, rather than actually predicting an ENSO event, the TOGA-TAO system picks up the very early stages of ENSO by monitoring changes in subsurface temperatures months before they become visible at the surface. Even with the TOGA-TAO observing system in the Pacific and the most advanced numerical models we cannot predict the onset of an ENSO event years in advance.

In the same way as the diurnal cycle or seasons are shaped by both external forcing and internal processes, the ocean circulation consists of components that can readily be explained and predicted from the action of the atmosphere on the ocean surface and an internal ("chaotic") variability. Examples of ocean circulation features that can be predicted from the wind, heat and freshwater forcings are the shape and position of ocean gyres with their intensified western boundary currents, the Antarctic Circumpolar Current (ACC), or seasonally varying currents e.g. in the equatorial regions or driven by seasonal up- and downwelling along continental west coasts in the subtropics. However, the ocean circulation is also modulated by internal variability that cannot directly be attributed to the forcing by winds and air-sea fluxes. This internal ocean variability depends on the actual conditions (temperature, salinity, velocities) of the ocean at any given time rather than on the atmospheric conditions. A wellknown example of ocean variability that is in general not directly linked to atmospheric variability is mesoscale ocean eddies, which can be regarded as the ocean equivalent of weather systems in the atmosphere (Williams et al., 2007). As for high- and low-pressure systems in the atmosphere the time and location of formation of ocean eddies depends on initial conditions; i.e. in a numerical ocean model even a small perturbation in the initial ocean conditions (temperature, salinity, velocities) will eventually lead to a different mesoscale eddy field, in the same way as perturbed initial conditions in a weather forecasting model will typically lead to different weather patterns in a matter of days. As with weather systems, we cannot predict the mesoscale eddy field a long time in advance even if the areas where ocean eddies tend to develop (e.g. along the Antarctic Circumpolar Current, in the Agulhas retroflection region, extensions of Kuroshio and Gulf Stream) are well known. The longer lifetimes and slower propagation of ocean eddies mean they can be predicted on longer timescales than their atmospheric counterparts. However, the ocean mesoscale eddy field generally becomes largely unpredictable on timescales of several months (Stammer, 1997). Mesoscale eddies may also interact with topography (e.g. when they approach a continental margin), which means that they can trigger waves such as baroclinic Kelvin and Rossby waves. As a consequence the baroclinic wave field will also be unpredictable to some extent. Note that the baroclinic wave field is more predictable than eddies since, e.g., Rossby waves generated by up- and downwelling along coastlines can readily be linked to atmospheric wind forcing.

The understanding of the potential predictability of ocean currents is a subject of ongoing research and is growing in importance. Operational ocean forecasting systems (e.g. Drevillon et al., 2008; Martin et al., 2007) now routinely provide weekly forecasts of the ocean conditions based on eddy-permitting and increasingly on eddy-resolving models. However, most research to date into the predictability of ocean currents such as the meridional overturning circulation (MOC) is based on coarse-resolution ocean models where mesoscale eddies are not resolved (Collins and Sinha, 2003; Hawkins and Sutton, 2009; Sévellec, 2008; Zanna and Tziperman, 2005). Ocean eddies are ubiquitous and therefore this raises the question how much they affect the variability of the ocean circulation not only in terms of temperatures, salinity, ocean colour, etc., but also how they 
impact the variability of components of the ocean circulation such as western boundary currents, or the MOC. The important role of eddies in the transport of heat, freshwater and in the mixing of water masses has been widely acknowledged (e.g. Jayne and Marotzke, 2001). However, how big an impact ocean eddies may leave on the variability of the MOC is far from fully understood, but is crucial for the interpretation of observational MOC estimates. The MOC plays a key role in maintaining the current climate in the North Atlantic region, and in recent years much effort has been dedicated to observing its strength and variability (Cunningham et al., 2007; Kanzow et al., 2009, 2010; Rayner et al., 2011). The variability inferred from such systems is affected by mesoscale ocean eddy activity, but it is difficult to quantify the effect. Based on the amplitude of the observed sea surface height (SSH) variability Wunsch (2008) suggests that the eddy imprint on meridional transports could exceed $20 \mathrm{~Sv}\left(1 \mathrm{~Sv}=10^{6} \mathrm{~m}^{3} \mathrm{~s}^{-1}\right)$. According to this study the MOC would therefore be potentially subject to a very large eddyrelated variability. This view was challenged in a study by Kanzow et al. (2009), who show that the large SSH variability which was projected onto meridional transports in Wunsch (2008) dramatically decreases close to the western margin. Furthermore, when moving closer to the western boundary the correlation between SSH and meridional transports gradually weakens, suggesting that SSH is not a good indicator for zonally integrated basin-wide transports. Therefore the projection of SSH anomalies onto the MOC is not straightforward (Kanzow et al., 2009; Hirschi et al., 2009). Nevertheless, the question of how large the imprint of unpredictable ocean processes on the MOC is remains, and in this study we use a global ocean model to investigate the forced and unpredictable or chaotic MOC components. The aim of the present paper is to provide an estimate of the dependence of the MOC on initial conditions across subannual to interannual timescales. In the remainder of this paper we will refer to the "initial-condition-dependent" MOC variability as the chaotic MOC variability. The model and method used in our study are presented in Sects. 2 and 3. Results showing the amplitude of the chaotic MOC variability are presented in Sect. 4. Our findings are discussed and summarised in Sects. 5 and 6.

\section{Model description}

The ocean model used in this study is the Nucleus for European Modelling of the Ocean (NEMO) in the ORCA025 and ORCA1 configurations (Madec, 2008). The ORCA025 configuration is similar to the one used in Blaker et al. (2012). For both resolutions, the model has 64 vertical levels with layer thickness increasing from $6 \mathrm{~m}$ at the surface to more than $200 \mathrm{~m}$ at the bottom. The surface forcing is obtained using 6-hourly winds and daily fluxes for heat and freshwater obtained from the DFS3 dataset (Brodeau et al., 2010) and the bulk formulation according to Large and Yeager (2004). For salinity a weak restoring with a time constant of 180 days is used to prevent salinities from drifting.

With a horizontal resolution of $1 / 4^{\circ}$ ORCA025 is eddypermitting, and a horizontal resolution of $1 / 4^{\circ}$ has been shown to produce a satisfactory mesoscale ocean eddy field up to mid-latitudes (e.g. Donners et al., 2004). Mesoscale eddy activity is also clearly seen at higher latitudes such as in the Antarctic Circumpolar Current. However, the dynamics of these eddies cannot be resolved at $1 / 4^{\circ}$ and the simulated eddy kinetic energy is lower than suggested by satellite observations (e.g. Penduff et al., 2010). For ORCA1 the horizontal resolution is $1^{\circ}$, except between $19.6^{\circ} \mathrm{N}$ and $19.6^{\circ} \mathrm{S}$ where the meridional resolution is smoothly increased to about $1 / 3^{\circ}$ at the Equator.

The results discussed in this paper are based on an ensemble of opportunity that was performed with ORCA025 and ORCA1 in the framework of the DRAKKAR project (http://www.drakkar-ocean.eu). The ensemble consists of two sets of twin experiments: one using ORCA025 and one using ORCA1. Each twin experiment consists of two passes through the surface forcing for the years 1958 to 2001. From here onwards the first passes in ORCA025 and ORCA1 will be referred to as experiments A025 and A100, while the second passes will be referred to as experiments B025 and B100. Both simulations A025 and A100 start from rest with initial conditions for temperatures and salinities taken from the World Ocean Atlas (Antonov et al., 1998). In experiments B025 and B100 the forcing for the 1958 to 2001 period is repeated, but now the ocean initial conditions are taken from the end of experiments A025 and A100 (i.e. the ocean state at the end of 31 December 2001).

Strong drifts are found in the ocean circulation during the first 10-15 yr of A025 and A100. These drifts are visible in transports such as the ACC and the MOC. After this initial phase the ocean transports reach a quasi steady state. Note that after this initial adjustment phase there is still a smaller long-term drift. For the MOC this long-term drift is typically about $2 \mathrm{~Sv}$ century ${ }^{-1}$ (compared with about $1 \mathrm{~Sv} \mathrm{yr}^{-1}$ at the beginning of A025 and A100). Long-term drifts are also found for water mass properties. These long-term drifts reflect the long-term adjustment of the ocean to the surface forcing. In particular for the water masses in the deep ocean this adjustment can take hundreds or even thousands of years - much longer than we can afford to run with ORCA025.

In the remainder of this study we will avoid the initial adjustment phase with strong MOC drifts and we will only consider the last $25 \mathrm{yr}$ of A025, A100, B025, and B100, i.e. the years 1976 to 2001. By comparing the last $25 \mathrm{yr}$ of the simulations (years 1976 to 2001) we ensure that we compare two experiments (A025/B025, A100/B100) that both start from initial conditions that are more consistent with the surface forcing than, e.g., the initial conditions at the start of the first pass which is based on temperatures and salinities from the World Ocean Atlas or the beginning of pass 2 

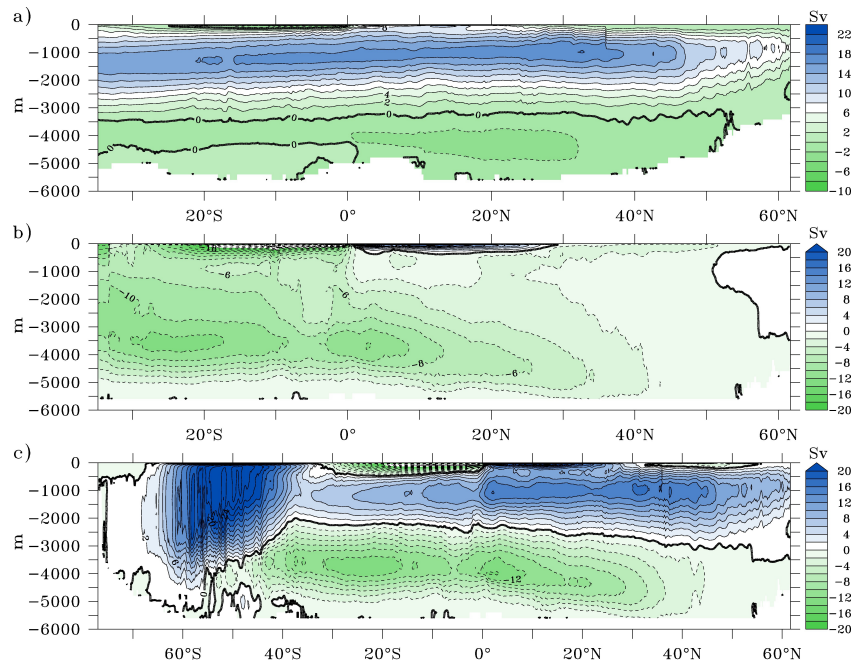

Fig. 1. Mean MOC for the 1976 to 2001 period of B025 for (a) the Atlantic, (b) the Indo-Pacific and (c) the global MOC. Contour interval is $2 \mathrm{~Sv}$.

where there is a temporal jump in the surface forcing (from 2001 back to 1958 forcing). Removing the first $18 \mathrm{yr}$ ensures that each simulation in the twin experiments A025/B025 and A100/B100 start from an ocean state with a mesoscale eddy field that has reached a statistical steady state. As mentioned above there is a drift in water mass properties when the initial conditions for A025/B025 and A100/B100 are considered. The initial conditions will therefore differ in the mesoscale eddy field (A025/B025); large-scale water mass properties, particularly for the deep ocean; and the phases of waves (A025/B025 and A100/B100). The atmospheric fields passed to the bulk formula are identical for both passes, and as a consequence the surface forcing is almost identical between the two passes. The only differences in forcing are due to the weak salinity restoring, as well as to the wind stress which depends on the relative velocity difference between the $10 \mathrm{~m}$ winds from DFS3 and on the surface ocean velocities. However, as we will show later the impact of these differences between the model passes is small.

The MOC strength and structure is similar for both model resolutions used here and is illustrated for experiment B025 for the 1976 to 2001 period (Fig. 1). In the Atlantic the MOC consists of two overturning cells linked to the formation of North Atlantic Deep Water (NADW) and Antarctic Bottom Water (AABW). The NADW cell ranges from the surface to depths of about $3000 \mathrm{~m}$. With values of about $16 \mathrm{~Sv}$ the maximum transport in the NADW cell occurs at $35^{\circ} \mathrm{N}$ at $1000 \mathrm{~m}$ depth. During the 1976 to 2001 period considered here the mean Atlantic MOC in NEMO is comparable to other similar models (e.g. Hirschi and Marotzke, 2007). At $26^{\circ} \mathrm{N}$ the MOC is around $16 \mathrm{~Sv}$, which is slightly weaker than the $18 \mathrm{~Sv}$ suggested by observations at that latitude (Cunningham et al., 2007; Kanzow et al., 2009; Rayner et
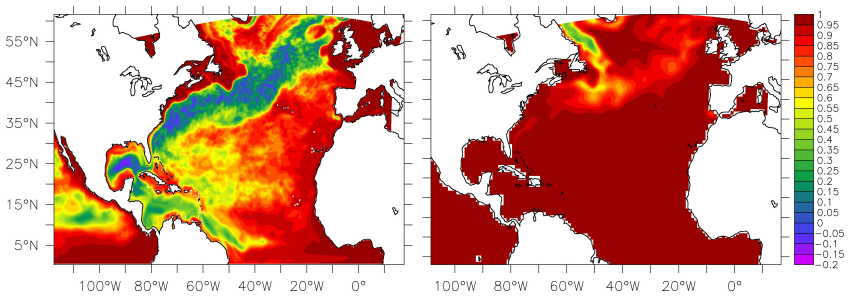

Fig. 2. Correlations between $\mathrm{SSH}$ variability in experiments A025 and B025 (left), and between SSH variability in A100 and B100 (right). The correlation values are obtained from 5-day averages.

al., 2011). The AABW cell fills the deep ocean below $3000 \mathrm{~m}$ and reaches maximum values of about $2 \mathrm{~Sv}$. The Indo-Pacific is dominated by the AABW cell, and apart from the uppermost layers which are dominated by Ekman transports, the AABW cell reaches its maximum values of $6-8 \mathrm{~Sv}$ between 3000 and $4000 \mathrm{~m}$ depth. In the following sections we will show that a careful comparison of the MOC variability found in A025/A100 and B025/B100 can be used to estimate the amplitude of the chaotic MOC variability on subannual to interannual timescales.

\section{Method}

The twin experiments A025/A100 and B025/B100 will now be used to estimate to what extent the MOC variability on sub- to interannual timescales is either directly forced by the atmosphere (i.e. deterministic) or dependent on initial conditions (i.e. chaotic). Since the prescribed atmospheric fields being fed into the bulk formula are identical, the surface forcing experienced by the ocean in the twin experiments is similar. We will show that differences between the twin experiments mainly arise from different initial conditions in the ocean.

Some of the differences between the model passes reflect the long-term model drift described in the previous section, and the initial conditions for the second model passes (experiments B025 and B100) do contain the model drift that occurred during the first passes (experiments A025 and A100). The model drift is a gradual and monotonic process (i.e. small drifts in the order of $2 \mathrm{~Sv}$ century ${ }^{-1}$ for the MOC in B025) which leads to changes in the long-term means of temperature, salinity, and currents. However, in addition to these long-term changes which reflect a long-term imbalance between the surface forcing and the ocean state, there are also differences between A025 and B025 (and A100, B100) that occur on shorter timescales. These differences are not monotonic (i.e. no gradual drift towards warmer/colder conditions or stronger/weaker transports) but can be of either positive or negative sign. Such changes can be illustrated when comparing the SSH in experiments A025 and B025. A large fraction of the SSH variability in A025 and B025 is due to mesoscale eddy activity (e.g. Penduff et al., 2011). The tim- 


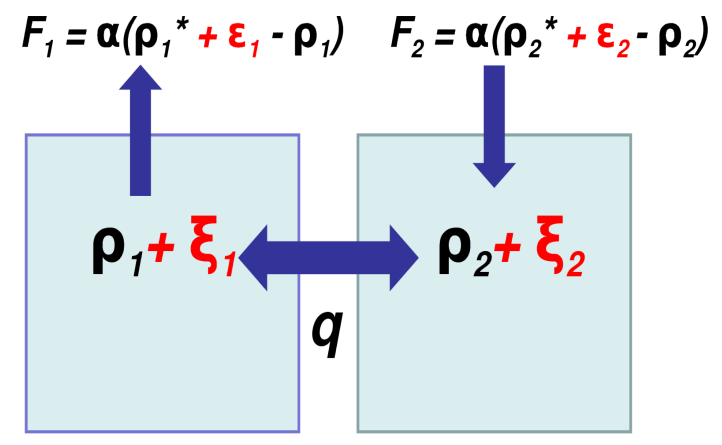

Fig. 3. Conceptual box model used to illustrate how to extract the chaotic MOC component from the NEMO experiments. See main text for explanations.

ing and location of eddies depend on initial conditions; i.e. if the same dates are considered in A025 and B025, then the mesoscale eddy fields are largely uncorrelated. This is illustrated for the North Atlantic in Fig. 2, which shows the correlation between 5-day mean SSH values in A025 and B025 as well as between A100 and B100. Regions where eddy variability is high in A025 and B025 (e.g. the Gulf Stream and North Atlantic Current) are characterised by correlations that are close to zero. These low correlations are not due to a systematic change in the SSH (i.e. a long-term model drift) but reflect SSH values fluctuating around similar mean values but with a timing that is different between experiments A025 and B025. Other regions where low correlations are found for the SSH between A025 and B025 are the Kuroshio and its eastward extension, the confluence of Brazil and Malvinas currents, the Agulhas region, and the Southern Ocean (not shown). As we expect the absence of mesoscale ocean eddies leads to much higher correlations between the SSH variability in experiments $\mathrm{A} 100$ and $\mathrm{B} 100$. This indicates that the chaotic variability is smaller in the ORCA1 simulations, but this will be discussed in more detail later in the paper.

Differences between the model passes 1 and 2 are not confined to SSH (i.e. mainly to the ocean eddy field) but will also be seen in ocean transports such as the MOC. To illustrate how we will quantify the amplitude of the chaotic MOC variability on sub- to interannual timescales we introduce a conceptual model. The basic setup of this simple box model (Fig. 3) consists of a Stommel-type two-box configuration (Stommel, 1961) which allows us to represent the exchange of water masses between high and low latitudes driven by a meridional density gradient.
The governing equations for the box model are

$$
\begin{aligned}
\rho_{1}(t+\Delta t) & =\frac{\left(\rho_{1}(t) \cdot\left(V_{1}-q \Delta t\right)+q \Delta t \rho_{2}(t)\right)}{V_{1}}+F_{1}(t) \Delta t \\
\rho_{2}(t+\Delta t) & =\frac{\left(\rho_{2}(t) \cdot\left(V_{2}-q \Delta t\right)+q \Delta t \rho_{1}(t)\right)}{V_{2}}+F_{2}(t) \Delta t \\
q(t) & =\beta\left(\rho_{1}(t)+\zeta_{1}(t)-\rho_{2}(t)-\zeta_{2}(t)\right) \\
F_{1}(t) & =\alpha\left(\rho_{1}^{*}+\epsilon_{1}(t)-\rho_{1}(t)\right) \\
F_{2}(t) & =\alpha\left(\rho_{2}^{*}+\epsilon_{2}(t)-\rho_{2}(t)\right),
\end{aligned}
$$

where $q$ is the transport between the two boxes and $\beta$ a constant scaling factor. $F_{1}, F_{2}$ are the air-sea fluxes where (nondimensional) pseudo densities $\rho_{1}, \rho_{2}$ are restored against $\rho_{1}^{*}$, $\rho_{2}^{*}$ with a time constant $\alpha . V_{1}, V_{2}$ are the box volumes and $\epsilon_{1}$, $\epsilon_{2}$ and $\zeta_{1}, \zeta_{2}$ are "atmospheric" and "oceanic" noise, respectively. The atmospheric noise consists of white noise that is added to the restoring values $\rho_{1}^{*}$ and $\rho_{2}^{*}$. The ocean noise $\zeta_{1}$, $\zeta_{2}$ depends on the actual values values of $\rho_{1}$ and $\rho_{2}$ and is obtained using the logistic equation $f(x)=r x(1-x)$. Depending on the value of $r$ the iteration of $f(x)$ leads to either periodic or non-periodic series of numbers between 0 and 1 (if $0<r<4$ ). We set the parameter $r$ to a value where the Lyapunov exponent is positive, i.e. where the iteration of the logistic equation does not lead to a periodic series of numbers $(r=3.8699)$. The ocean noise $\zeta_{1,2}$ is calculated by iterating the logistic equation 100 times:

$\zeta_{1}(t)=\left(f^{100}\left(x_{1}(t)\right)-0.5\right) / 20$,
$\zeta_{2}(t)=\left(f^{100}\left(x_{2}(t)\right)-0.5\right) / 20$.

Subtracting 0.5 ensures a spread of positive and negative values for $\zeta_{1}, \zeta_{2}$, and the scaling by 20 ensures that $\zeta_{1}, \zeta_{2}$ do not result in excessively large anomalies in the transport $q$. The values of $x_{1}, x_{2}$ depend on the value of $\rho_{1}$ and $\rho_{2}$ according to

$x_{1}(t)=0.5+\rho_{1}(t) / 2000$,

$x_{2}(t)=0.5+\rho_{2}(t) / 2000$,

which ensures a small variability in the initial conditions of the iteration of $f$.

The conceptual model allows us to produce analogues to the NEMO experiments A025/B025 (and A100/B100). The chaotic variability in two box model passes can be considered as two independent samples overlaid onto the variability directly predictable from the surface forcing. To estimate the amplitude of chaotic ocean variability in the transport $q$ we can simply run the model with and without ocean noise (i.e. $\left.\zeta_{1,2}(t) \neq 0, \zeta_{1,2}(t)=0\right)$. The atmospheric noise $\epsilon_{1,2}(t)$ is the same in both box model runs. Apart from an initial spin-up phase, the difference between $q$ in two such runs is then due to differences in the noise $\zeta_{1,2}(t)$ (i.e. the "chaotic ocean variability", Fig. 4). The amplitude of the chaotic variability in $q$ can therefore be quantified by simply calculating the standard deviation of the difference between model passes where $\zeta_{1,2}(t) \neq 0$ and $\zeta_{1,2}(t)=0$. 


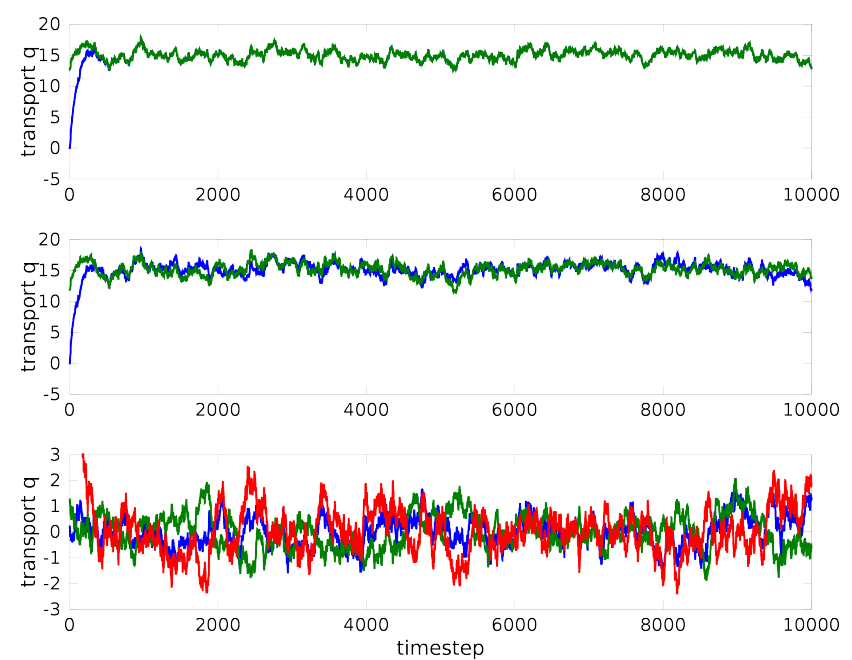

Fig. 4. Results from conceptual box model. Top: two model passes without chaotic ocean variability (spin-up: blue; second pass: green). Middle: two model passes with chaotic ocean variability (blue: spin-up; green: second pass). Bottom: differences between the spin-ups (blue), the second passes (green), and between the spinup and the second pass for the case with added chaotic ocean variability (red).

If $\zeta_{1,2}(t) \neq 0$ in passes 1 and 2 the standard deviation of the difference exceeds the amplitude of the chaotic variability because of the independence of $\zeta_{1,2}(t)$ in both passes (Fig. 4).

Generally the standard deviation of the difference between two time series is

$\sigma\left(q_{1}-q_{2}\right)^{2}=\sigma\left(\Delta q_{1}\right)^{2}+\sigma\left(\Delta q_{2}\right)^{2}-2 \cdot \operatorname{cov}\left(\Delta q_{1}, \Delta q_{2}\right)$,

where $\sigma$ denotes the standard deviation, cov the covariance, and $\Delta q_{1,2}$ the differences between $q$ obtained with $\zeta_{1,2}=0$ and $q$ obtained with two different realisations of $\zeta_{1,2} \neq 0$. For uncorrelated time series (as is the case for different realisations of the ocean noise $\zeta_{1,2}(t)$ the standard deviation for the difference $q_{1}-q_{2}$ exceeds the standard deviation of $\Delta q_{1,2}$ by a factor of $\sqrt{2}$; i.e. to obtain the correct estimate of the amplitude of the chaotic ocean variability $\sigma\left(q_{1}-q_{2}\right)$ needs to be scaled by $1 / \sqrt{2}$. As shown in Eq. (10) the scaling factor can change between 0 (perfect correlation of the noise between both model passes) and 2 (perfect anticorrelation, Fig. 5).

The simple box model illustrates that the difference between two NEMO simulations with the same atmospheric forcing but different chaotic ocean variability overestimates the amplitude of the chaotic ocean variability. The main driver of chaotic variability in NEMO at high resolution is the presence of mesoscale eddies. As shown previously the correlations between the eddy fields in experiments A025 and B025 are low (Fig. 2), and for the remainder of this study we will assume that the imprint of eddies (and to a lesser extent also of waves) are decorrelated in experiments A025 and B025. As in the box model we will use the standard deviation of the differences between $\mathrm{A} 025$ and $\mathrm{B} 025$ (and between

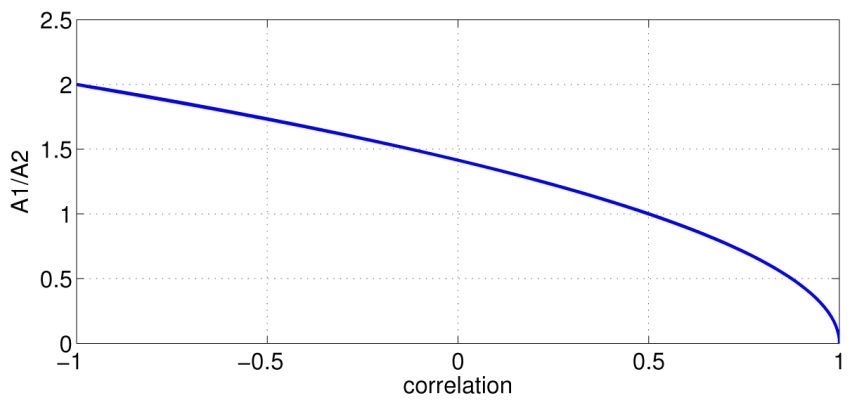

Fig. 5. Scaling factor for differences between two time series.

A100 and B100) to provide a measure of the amplitude of the chaotic MOC variability.

Note that the method introduced above will allow us to provide a quantitative estimate of the chaotic MOC variability in a statistical sense. This means that we will only be able to make statements about the chaotic MOC variability on timescales that are short compared to the duration of the simulations. Since we want to avoid the initial phase of the model integrations where strong drifts occur, we are limited to $25 \mathrm{yr}$-long datasets (period from 1976 to 2001). We can therefore obtain estimates of the standard deviation of the chaotic MOC variability on subannual to interannual timescales, but we will not be able to comment on the likely amplitude of the chaotic MOC variability on decadal timescales.

\section{Results}

The approach introduced in Sect. 3 is now applied to the years 1976 to 2001 of the NEMO experiments A025, B025, A100, and B100.

\subsection{MOC variability}

The MOC variability in experiments A025 and B025 ranges from subdaily to interannual timescales (Blaker et al., 2012). The short duration of the simulation means that we cannot comment on decadal and longer timescales. Since we use 5-day averages we also cannot address to what extent the subdaily MOC variability generated by near-inertial gravity waves (Blaker et al., 2012) is affected by chaotic processes. Based on 5-day averages the largest standard deviations for the MOC in the Atlantic are typically around 3-4 Sv at midto high latitudes (Fig. 6a). A much larger variability characterises the equatorial region where the standard deviation reaches up to $23 \mathrm{~Sv}$. A similar variability pattern is found for the Indo-Pacific (Fig. 6b). The main difference is that the standard deviation is 2-3 times larger. At mid-latitudes values are typically between $6-8 \mathrm{~Sv}$, while values of up to $60 \mathrm{~Sv}$ are found at the Equator. The larger MOC variability in the Indo-Pacific is mainly due to the much wider basin, 

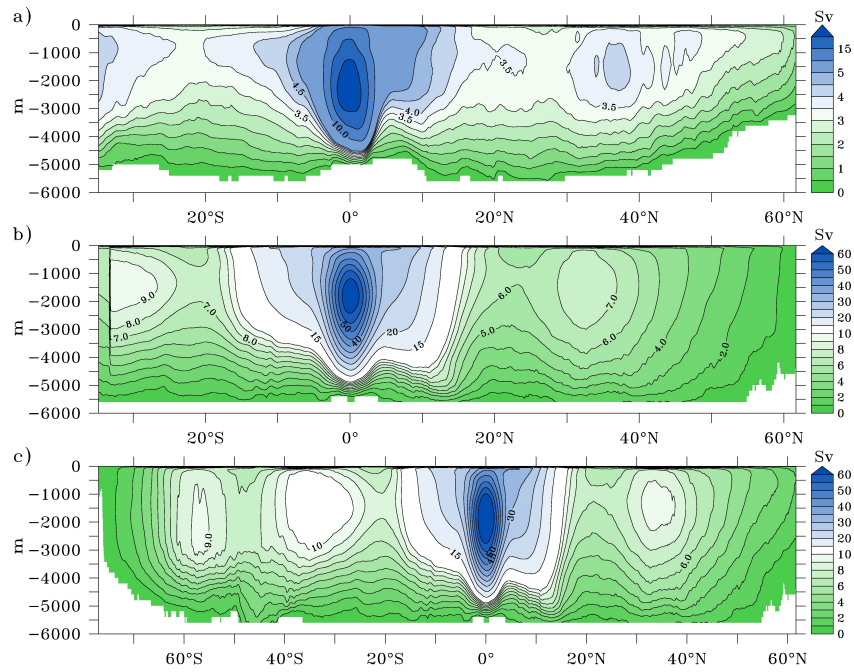

Fig. 6. Standard deviation of the MOC for the 1976 to 2001 period for experiment B025. The values are obtained from 5-day averages. (a) Standard deviation for the Atlantic. The contour interval is $0.5 \mathrm{~Sv}$ for values of up to $5 \mathrm{~Sv}$. For standard deviations $>5 \mathrm{~Sv}$ the contour interval is $5 \mathrm{~Sv}$. (b) As (a) for the Indo-Pacific. For values $<10 \mathrm{~Sv}$ (>10 Sv) the contour interval $1 \mathrm{~Sv}(5 \mathrm{~Sv})$. (c) As (b ) for the global MOC.

which allows for higher values in Ekman transport and in its variability. An interesting feature is the very high variability found at the Equator. Whereas a maximum MOC variability at the Equator is expected (e.g. Jayne and Marotzke, 2001), the values found in NEMO are higher than those found in other models. There is only little dependence of the equatorial variability on the model resolution. In experiments A100 and B100 the maximum standard deviation for the MOC at the Equator is $20 \mathrm{~Sv}$ in the Atlantic - only marginally smaller than the value found in experiments A025 and B025 (not shown). Trying to explain why NEMO produces a higher equatorial variability than other ocean models is beyond the scope of this paper and is the subject of ongoing research. The only other model we are aware of that produces a similar variability is the model from the Los Alamos Parallel Ocean Program (POP) (Alicia Karspeck, personal communication).

In analogy to the simple box model introduced earlier, the correlations between the model passes 1 and 2 are high (Fig. 7). This is illustrated for $\mathrm{A} 025$ and $\mathrm{B} 025$ at $26^{\circ} \mathrm{N}$ in the Atlantic and in the Indo-Pacific. In the Atlantic (Indo-Pacific) the MOC is slightly weaker (stronger) in B025 than in A025, but the timing of MOC peaks and troughs remains essentially the same in both model passes (Fig. 7a, b, d, e). However, the temporal agreement between both model passes is not perfect. The difference in transports between A025 and B025 is not just a constant offset or gradually increasing/decreasing (e.g. due to model drift), but it exhibits peaks and troughs with a typical duration of a few months (Fig. 7c, f). In both the Atlantic and Indo-Pacific the amplitude of the MOC dif- a)
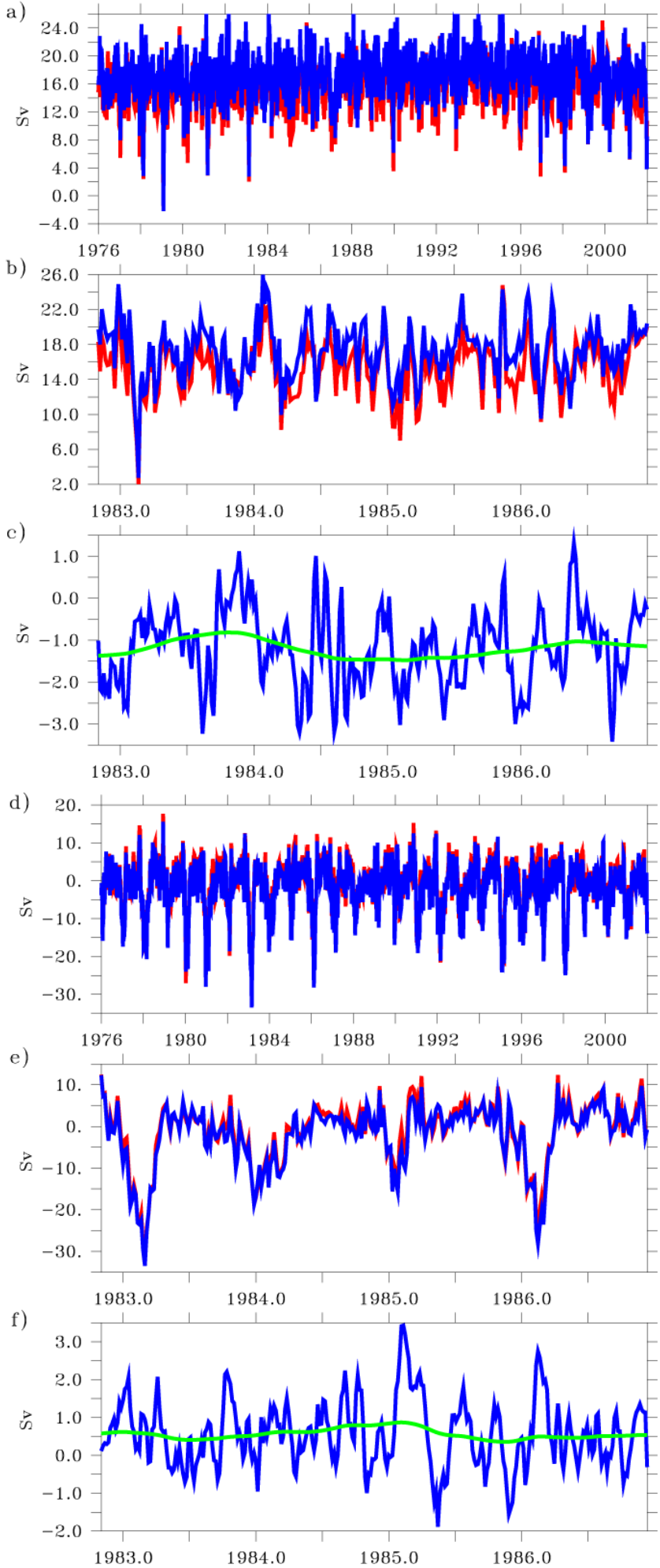

Fig. 7. MOC time series at $26^{\circ} \mathrm{N}$ for experiment A025 (blue) and B025 (red) for (a), (b), (c) the Atlantic and (d), (e), (f) Indo-Pacific. (a), (d) 5-day MOC averages at $1000 \mathrm{~m}$ for 1976 to 2001. (b), (e) zoom on the years 1983 to 1987 . (c), (f) MOC differences between A025 and B025 scaled by $1 / \sqrt{2}$ as unfiltered (blue) and smoothed values. The smoothing was done using a Parzen filter with a window length of 505 days (green). 

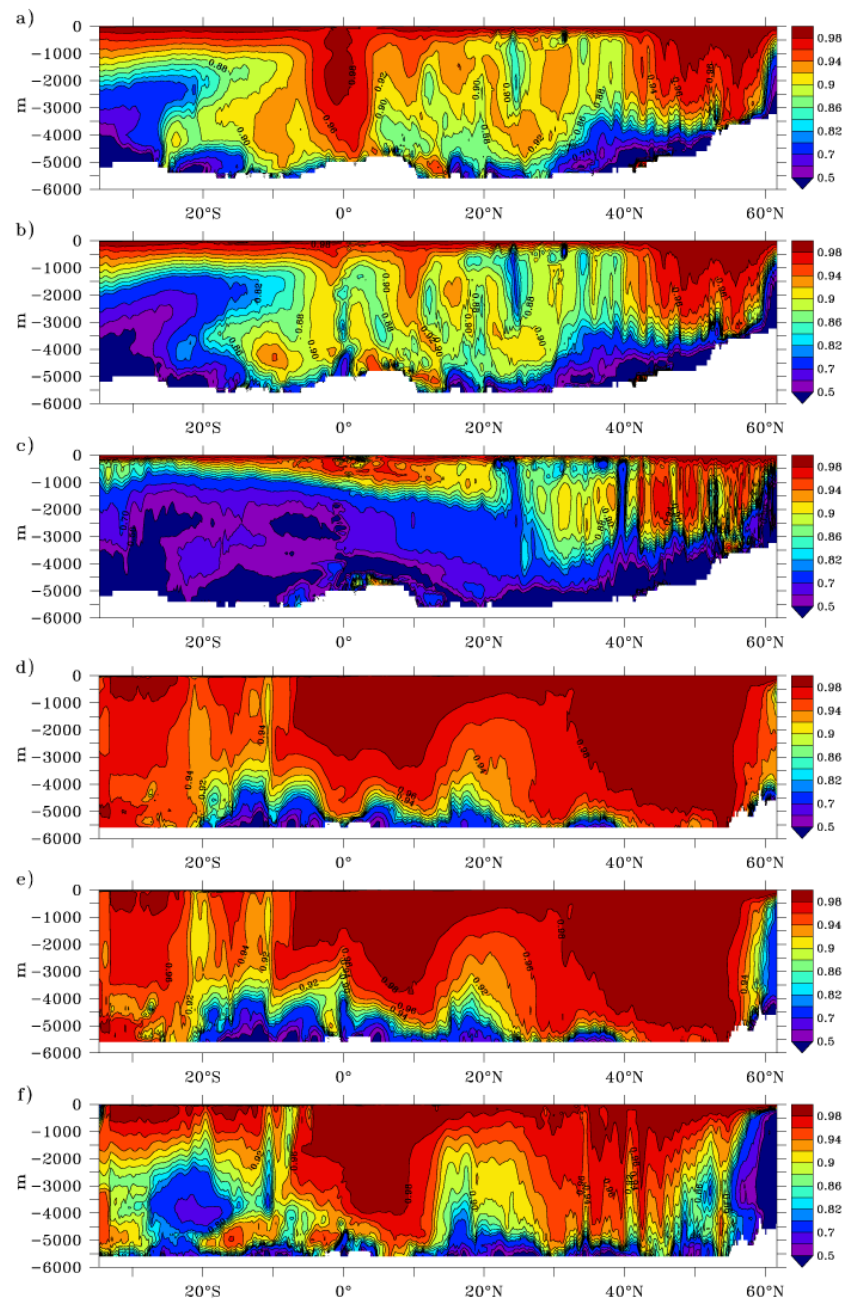

Fig. 8. Correlations between the MOC in the NEMO simulations A025 and B025 for the 1976 to 2001 period. (a), (b), (c) Correlations for the unfiltered Atlantic MOC for unfiltered (5-day averages) (a) subannual (b) and interannual (c) MOC variability. (d), (e), (f) As panels (a), (b), (c) but for the Indo-Pacific basin. For correlations higher (lower) than 0.8 the contour interval is $0.02(0.1)$.

ference between A025 and B025 exhibit peak-to-peak differences that can exceed $5 \mathrm{~Sv}$. In accordance to the findings from the box model we have scaled the difference between the two model passes by $1 / \sqrt{2}$. In the remainder of the paper we will look at the unfiltered values (i.e. 5-day averages) of MOC or of the difference between both model passes as well as at the subannual and interannual components of the variability. The interannual variability is obtained by smoothing the MOC with a Parzen filter, and the subannual variability is then given by the difference between the unfiltered and the filtered time series (Fig. 7c, f).

Correlations between A025 and B025 for the MOC as a function of latitude and depth show that at most depths the correlations are 0.8 or higher in all the regions examined (Atlantic, Indo-Pacific and Southern Ocean, Figs. 8 and 9).
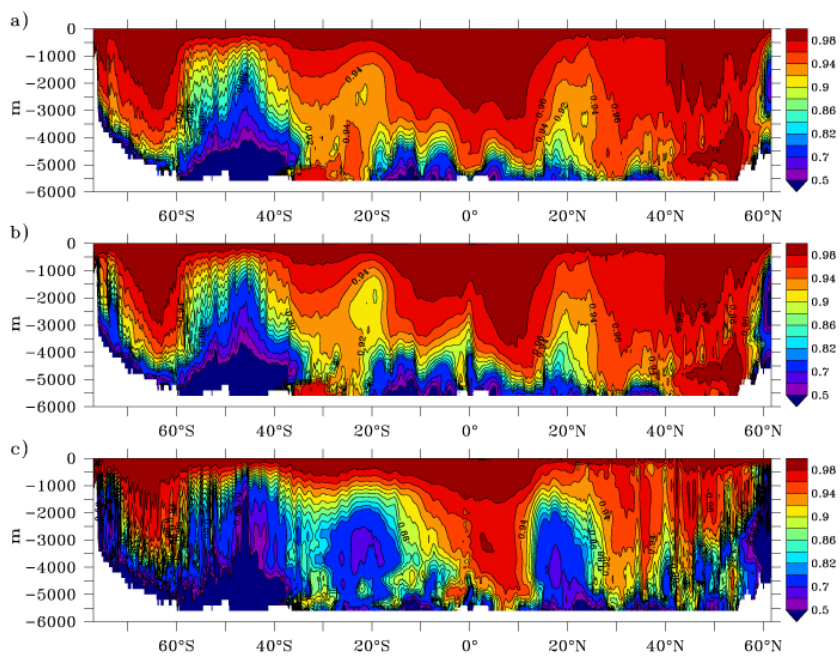

Fig. 9. As Fig. 8(a), (b), (c) but for global MOC.

In the surface layers correlations are higher than 0.96 at all latitudes on both sub- and interannual timescales. This is expected as the MOC in the surface layers is dominated by Ekman transports. Given that the same atmospheric forcing fields are passed to the bulk formula Large and Yeager (2004) in the twin experiments the surface wind stress experienced by the ocean in the twin simulations will be similar. Note that the wind stress is not exactly the same in the twin runs since it depends on the difference between the wind speed and the ocean velocities. The ocean velocities for any given time and location will differ between the twin runs, which leads to the ocean experiencing a different wind stress. However, our results show that the impact of different ocean velocities on the wind stress is small when we look at zonally integrated transports such as the MOC and that very similar Ekman transports occur in both A025 and B025. The lowest correlations of 0.6 or less are found in the bottom layers. At these depths the MOC variability is small compared to the maximum values found between 1000 and $1500 \mathrm{~m}$ and has a standard deviation of $1 \mathrm{~Sv}$ or less (Fig. 6). Correlations between A025 and B025 are higher in the Indo-Pacific than in the Atlantic. As before this can be explained by the dominance of Ekman variability in the Pacific MOC. Since the wind fields prescribed in A025 and B025 are identical the resulting wind stresses will be very similar. The same holds true for the Atlantic; but firstly, the Atlantic is narrower, which means weaker Ekman transports and variability, and secondly, the Atlantic is characterised by the clockwise overturning cell linked to deep water formation in the Nordic Seas (Fig. 1). The total variability of the Atlantic overturning cell contains a large contribution from geostrophic transports (Hirschi et al., 2007; Cunningham et al., 2007). In the Indo-Pacific this contribution is much smaller.

It is also interesting to note that correlations are very high $(>0.9)$ at the Equator in both the Atlantic and the 

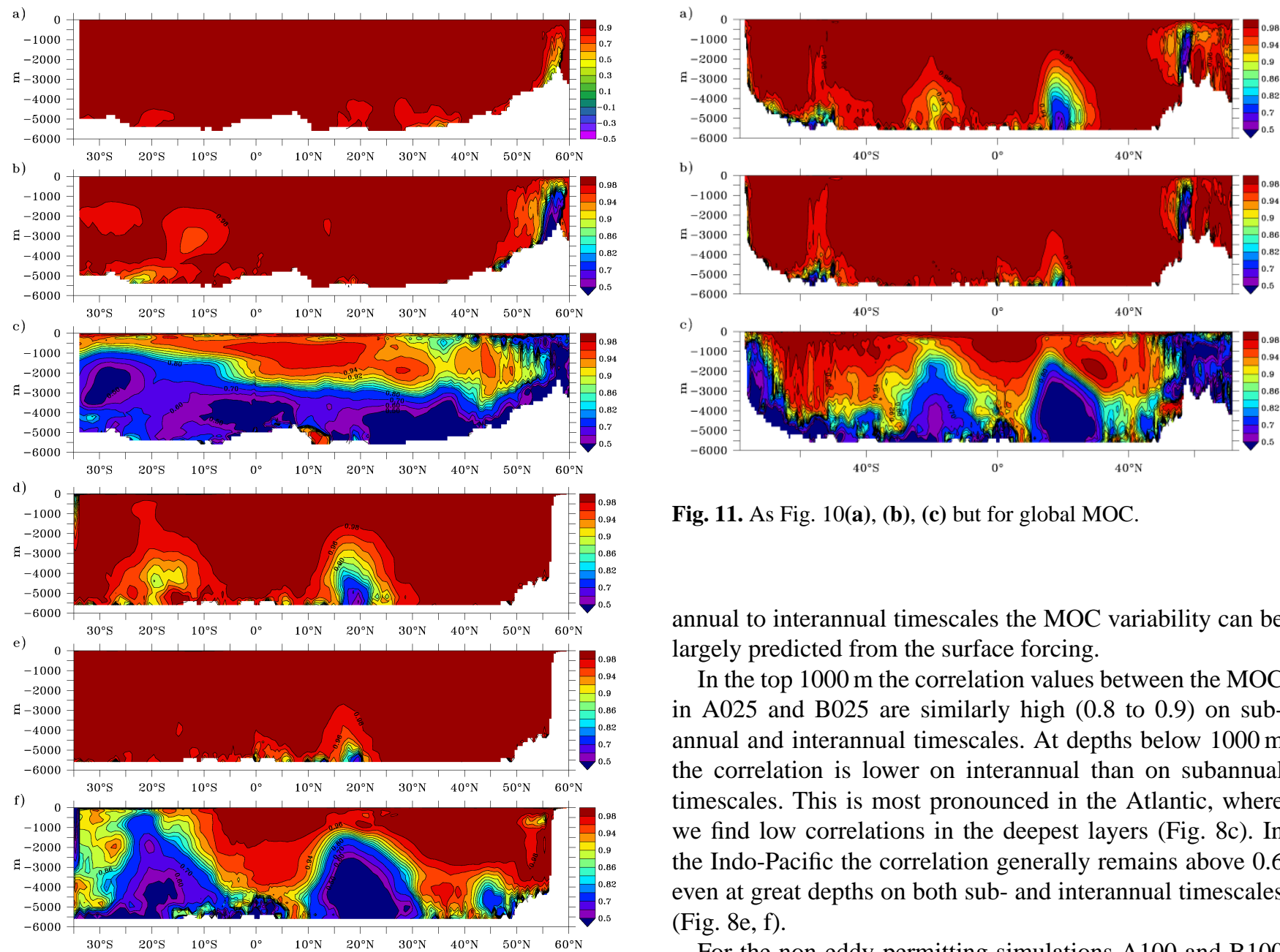

Fig. 11. As Fig. 10(a), (b), (c) but for global MOC.

Fig. 10. Correlations between the MOC in the NEMO simulations A100 and B100 for the 1976 to 2001 period. (a), (b), (c) Correlations for the unfiltered Atlantic MOC for unfiltered (5-day averages) (a) subannual (b) and interannual (c) MOC variability. (d), (e), (f) As panels (a), (b), (c) but for the Indo-Pacific basin. For correlations higher (lower) than 0.8 the contour interval is $0.02(0.1)$.

Indo-Pacific. This suggests that the large equatorial variability described earlier can largely be predicted from the surface forcing. The lowest correlations are found south of $30^{\circ} \mathrm{S}$ in the Atlantic and at the latitudes of the ACC for the global MOC (Fig. 9). However, even for these locations the correlations are higher than 0.7 at the depths where the maximum MOC occurs. A reduced correlation in the South Atlantic can be expected as this region is affected by Agulhas rings that are shed at the southern tip of Africa and which have been shown to affect the MOC variability (Biastoch et al., 2008). As with other ocean eddies the timing of the formation of Agulhas rings depends more on the ocean conditions than on the surface forcing at the time when the ring forms. In summary, the high correlations between the two model passes A025 and B025 shown in Figs. 8 and 9 suggest that on sub-

annual to interannual timescales the MOC variability can be largely predicted from the surface forcing.

In the top $1000 \mathrm{~m}$ the correlation values between the MOC in A025 and B025 are similarly high (0.8 to 0.9) on subannual and interannual timescales. At depths below $1000 \mathrm{~m}$ the correlation is lower on interannual than on subannual timescales. This is most pronounced in the Atlantic, where we find low correlations in the deepest layers (Fig. 8c). In the Indo-Pacific the correlation generally remains above 0.6 even at great depths on both sub- and interannual timescales (Fig. 8e, f).

For the non-eddy-permitting simulations A100 and B100 the correlations are higher than 0.9 almost everywhere in the Atlantic, the Indo-Pacific and global ocean (Figs. 10 and 11). An interesting difference with experiments A025/B025 are the different contributions from the sub- and interannual variability to the correlations obtained for the total MOC variability. The correlation patterns found for A025/B025 mainly reflect the correlation patterns found on subannual timescales. This suggests that most of the uncorrelated variability between A025 and B025 is found on subannual timescales. This is not the case for experiments A100/B100, where on subannual timescales the correlations are 0.96 or better almost everywhere for the Atlantic, Indo-Pacific and global ocean. The slightly reduced correlation values between A100 and B100 found for the total MOC variability therefore have their origin in the interannual MOC variability.

For both sets of experiments the patterns for the interannual MOC variability show reduced correlation values in the deep ocean. This is most clearly seen in the Atlantic but also to a lesser extent for the Indo-Pacific and global ocean. For A025/B025 these reduced correlations do not project much onto the correlations found for the total MOC variability because the interannual MOC variability only accounts for a 

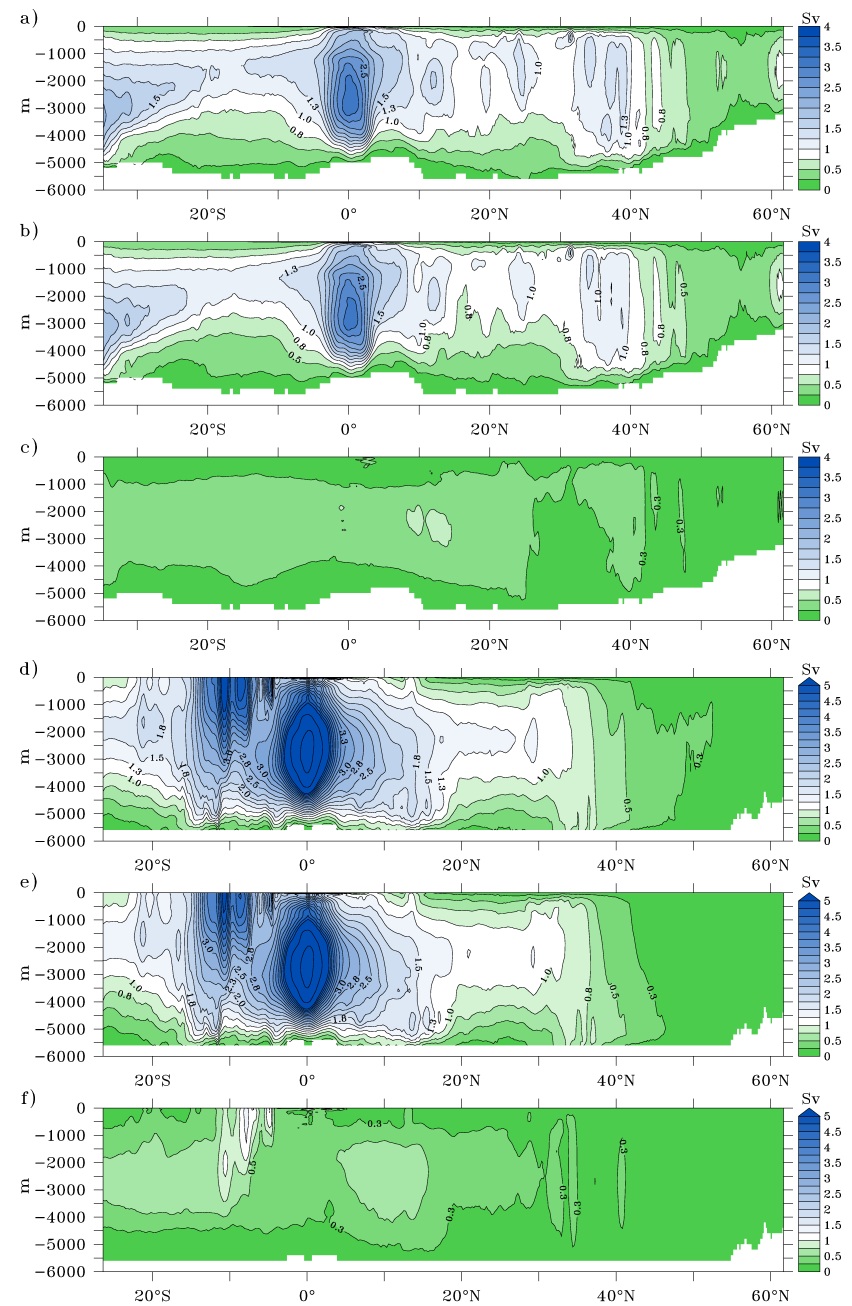

Fig. 12. Chaotic Atlantic (a), (b), (c) and Indo-Pacific (d), (e), (f) MOC variability for the eddy-permitting experiments (A025, B025). (a) Unfiltered chaotic MOC variability (based on 5-day averages). (b) Subannual chaotic MOC variability. (c) Chaotic MOC variability on interannual timescales. (d), (e), (f) as (a), (b), (c) but for Indo-Pacific. Units are $\mathrm{Sv}$ and the contour interval is $0.25 \mathrm{~Sv}$.

small fraction of the total MOC variability in our experiments. The low correlations found at depth on interannual timescales are likely to be linked to differences in the phases of baroclinic waves between A025/B025 and A100/B100. Baroclinic Rossby waves have been associated with MOC variability (Hirschi et al., 2007). In particular the phase difference of Rossby waves between the eastern and western margins have the potential to affect the MOC transport on interannual timescales (Hirschi et al., 2007). The phases of topographic Rossby waves in particular at the eastern and western margins can differ between model passes, providing a possible mechanism for the low correlations found on interannual timescales. In addition there is likely to be some cascading from mesoscale ocean eddies into longer timescales in experiments A025 and B025 (e.g. Penduff et al., 2011).
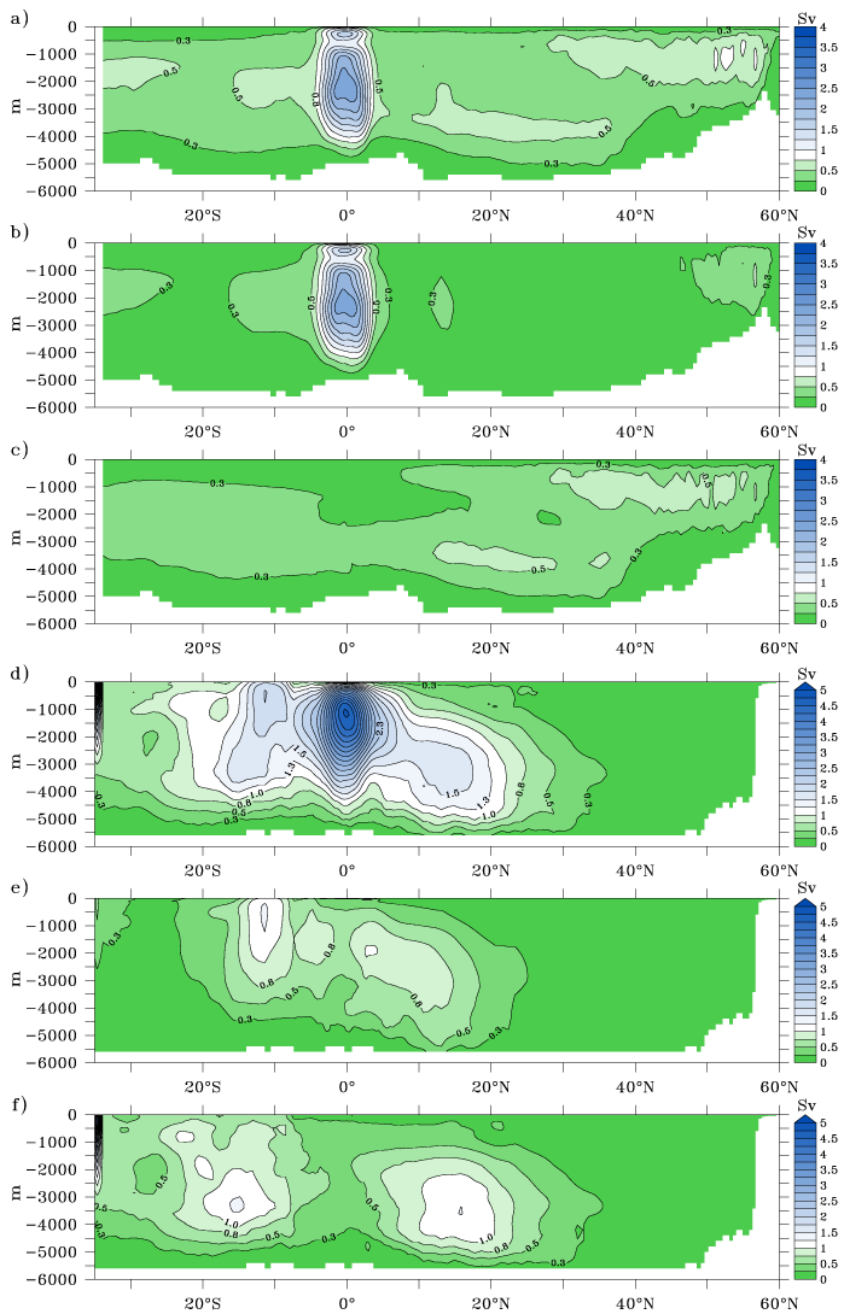

Fig. 13. Chaotic Atlantic (a), (b), (c) and Indo-Pacific (d), (e), (f) MOC variability for the non-eddying experiments (A100, B100). (a) Unfiltered chaotic MOC variability (based on 5-day averages). (b) Subannual chaotic MOC variability. (c) Chaotic MOC variability on interannual timescales. (d), (e), (f) as (a), (b), (c) but for IndoPacific. Units are Sv and the contour interval is $0.25 \mathrm{~Sv}$.

On subannual timescales we only find low correlations at depth for A025/B025, which suggests a projection of mesoscale ocean eddies onto the MOC throughout the water column. Such a variability would be decorrelated between A025 and B025. Whereas this variability may not affect the correlations for the total MOC at the depths where the MOC variability is high, it may leave an imprint at greater depth where the overall MOC variability is much weaker (Fig. 6).

\subsection{Chaotic MOC variability}

The correlation between the MOC in A025 and B025 is high. Nevertheless, looking at the difference between the model passes shows that there is a non-negligible fraction of the MOC variability that cannot directly be linked to the surface 

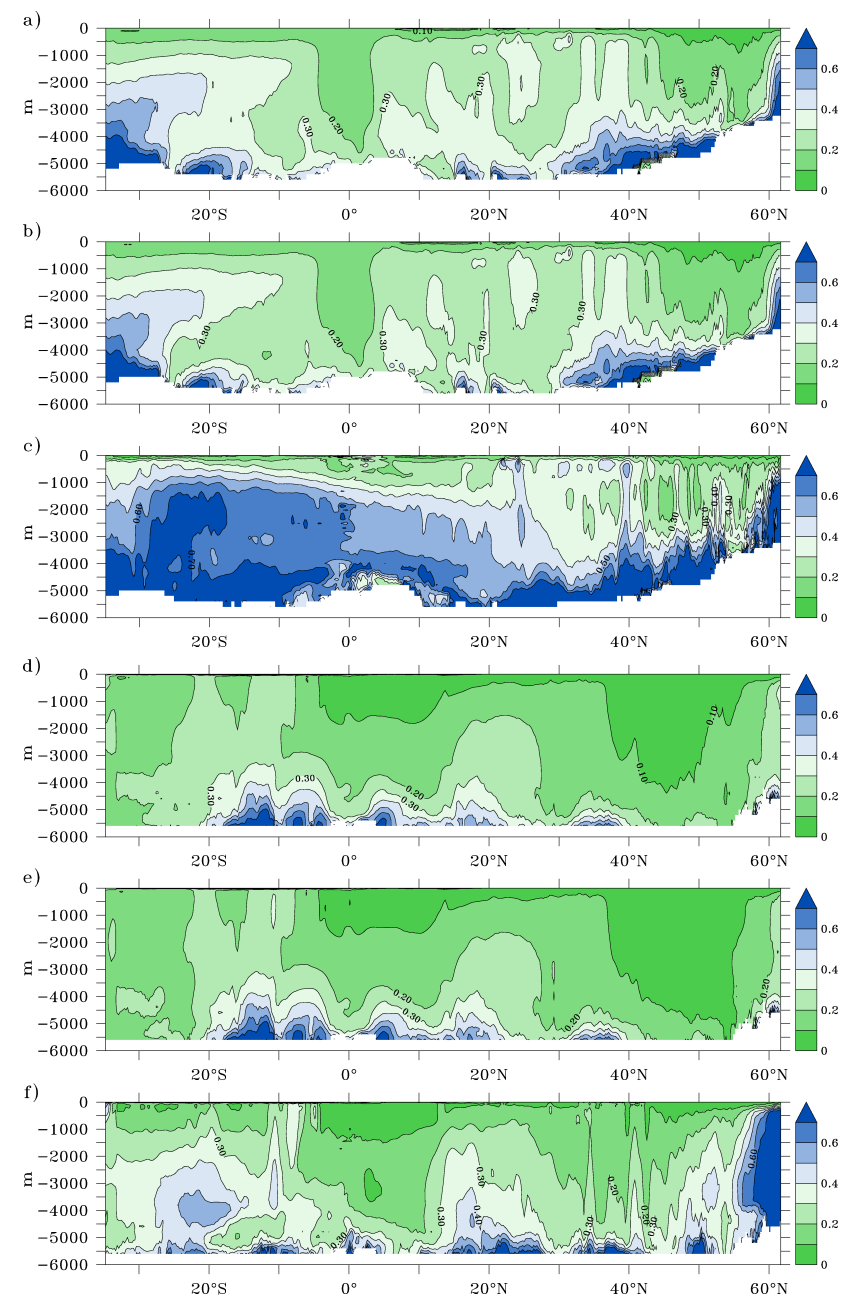

Fig. 14. Ratio between chaotic and total MOC variability for the Atlantic (a), (b), (c) and Indo-Pacific (d), (e), (f) in the eddypermitting experiments A025/B025. (a) Ratio for unfiltered MOC variability (based on 5-day averages). (b) Ratio for subannual MOC variability. (c) Ratio for interannual MOC variability. (d), (e), (f) as (a), (b, (c) but for Indo-Pacific. The contour interval is 0.1 .

forcing. In analogy to the box model we calculate the amplitude of the chaotic MOC variability according to

$\Psi_{c h a}(y, z, t)=\left(\Psi(y, z, t)_{A 025}-\Psi(y, z, t)_{B 025}\right) / \sqrt{2}$,

$\Psi_{c h a}(y, z, t)=\left(\Psi(y, z, t)_{A 100}-\Psi(y, z, t)_{B 100}\right) / \sqrt{2}$,

where $\Psi(y, z)_{A 025 / 100}$ and $\Psi(y, z)_{B 025 / 100}$ are the meridional streamfunctions for the model passes A025 and B025, respectively, A100 and B100. As for the correlations we just discussed we look at the total, subannual and interannual chaotic MOC variability (Figs. 12 and 13). In the Atlantic (Fig. 12a, b, c) the standard deviation of the chaotic MOC variability $\Psi_{\text {cha }}$ for the eddy-permitting experiments reaches more than $3 \mathrm{~Sv}$ at the Equator at a depth of $3000 \mathrm{~m}$. Away from the Equator the maximum variability is typically between 0.8 and $1.5 \mathrm{~Sv}$ and occurs at depths between
1000 and $3000 \mathrm{~m}$. The chaotic MOC variability is larger in the South Atlantic with values of up to $2 \mathrm{~Sv}$ at the southern limit of the domain. Looking at the subannual variability reveals that most of this chaotic MOC variability occurs on short timescales. The values for the standard deviation of the subannual chaotic MOC variability are only slightly reduced compared with the values found for the total chaotic MOC. On interannual timescales the chaotic MOC variability is much smaller with values of less than $0.5 \mathrm{~Sv}$ over most of the Atlantic domain.

For the Indo-Pacific (Fig. 12d, e, f) we also find a pronounced variability maximum in $\Psi_{c h a}$ at the Equator with a standard deviation of up to $7 \mathrm{~Sv}$ (Fig. 12d, e). As in the Atlantic this equatorial variability occurs on subannual timescales. Apart from a band of latitudes between $15^{\circ} \mathrm{S}$ and $15^{\circ} \mathrm{N}$ the standard deviation of the subannual variability in $\Psi_{\text {cha }}$ is between 1 and $1.5 \mathrm{~Sv}$ - values which are similar to the chaotic variability found in the Atlantic. On interannual timescales the chaotic MOC variability in the Indo-Pacific is $0.5 \mathrm{~Sv}$ or less at most latitudes. Again this is comparable with the Atlantic values.

In experiments A100/B100 the total chaotic MOC variability is much reduced (Fig. 13). Away from the Equator the chaotic MOC variability is generally less than $0.5 \mathrm{~Sv}$ in the Atlantic and $1 \mathrm{~Sv}$ in the Indo-Pacific. In contrast with the eddy-permitting model this variability is largely found on interannual timescales (except at the Equator). The amplitude of the interannual chaotic MOC variability is comparable to that found in the eddy-permitting experiments A025 and B025. In some regions (e.g. north of about $30^{\circ} \mathrm{N}$ in the Atlantic, and in the deep Indo-Pacific between $10^{\circ}$ and $25^{\circ} \mathrm{N}$ ) the interannual chaotic MOC variability exceeds that found for experiments A025 and B025. Except at the Equator the subannual chaotic MOC variability is generally less than $0.3 \mathrm{~Sv}$ (Atlantic) and $0.8 \mathrm{~Sv}$ (Indo-Pacific). The maximum values for the subannual chaotic MOC variability are reached at the Equator, with values of about $2.5 \mathrm{~Sv}$ in the Atlantic and $4 \mathrm{~Sv}$ in the Indo-Pacific. In the indo-Pacific there is a change in the vertical structure of the subannual chaotic MOC variability at the Equator. In A100/B100 the maximum variability occurs at a depth of about $1500 \mathrm{~m}$, whereas the maximum variability is found at $3000 \mathrm{~m}$ depth in experiments A025/B025. The reduction in subannual chaotic MOC variability in A100/B100 is less pronounced at the Equator than at other latitudes, and as in A025/B025 the subannual variability accounts for almost all the chaotic MOC variability in the equatorial region. The reduced difference in chaotic MOC variability between experiments A100/B100 and A025/B025 at the Equator is expected since ORCA1 uses a regionally increased resolution of $1 / 3^{\circ}$ at low latitudes. Features which are likely to contribute to the large chaotic variability at the Equator (e.g. tropical instability waves) are therefore present in both sets of experiments.

The ratio of the chaotic to the total MOC variability can be given as the ratio $\Psi_{\text {cha }} / \Psi$ (Fig. 14). The lowest ratios 

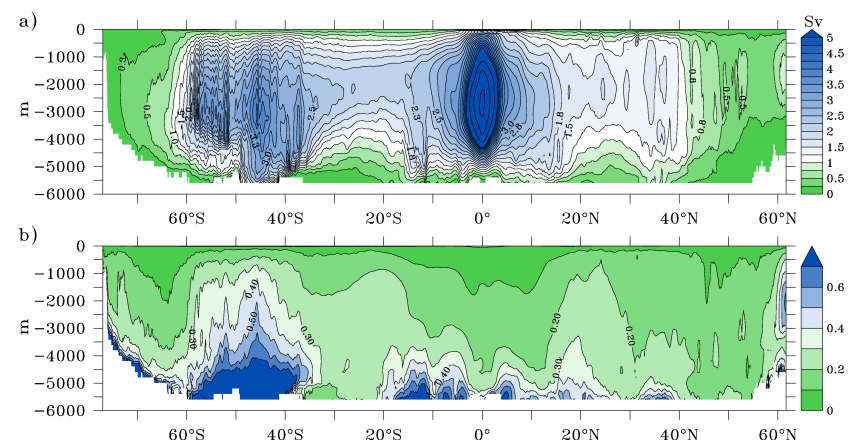

Fig. 15. (a) Unfiltered chaotic variability for global MOC. The contour interval is $0.25 \mathrm{~Sv}$ for values of up to $5 \mathrm{~Sv}$. For values higher than $5 \mathrm{~Sv}$ the contour interval is $1 \mathrm{~Sv}$. (b) Ratio between standard deviations of chaotic and total global MOC.

are found in the top few hundred metres. This is expected as a large fraction of the MOC variability in the top layers is due to variability in the Ekman transports which only differ slightly between the two model passes. The ratio gradually increases with depth, and at $1000 \mathrm{~m}$, which is approximately where the MOC typically reaches its maximum, values are mostly between 0.2 and 0.3 . It is noteworthy that even though the largest MOC variability is found at the Equator, this region coincides with the low ratios $(<0.2)$ between chaotic and total MOC variability. This low ratio is consistent with the high correlations found at the Equator (Fig. 8) and confirms that the large equatorial MOC variability in NEMO is highly predictable from the surface forcing.

The highest ratios mostly occur at the bottom with values that can be in excess of 1 . However, at great depths the MOC variability is small compared to the values found around the depths where the maximum MOC occurs (Fig. 6). Between depths of 1000 and $3000 \mathrm{~m}$, the highest ratios in the Atlantic are found south of $20^{\circ} \mathrm{S}$ with values between 0.3 and 0.5 (Fig. 14a). This is higher than the corresponding ratios found in the North Atlantic. The increased fraction of chaotic MOC variability in the South Atlantic is likely to be linked to strong eddy activity at the southern limit of the region as will be discussed in more detail in Sect. 5. An interesting feature is that the ratio between the chaotic and total MOC variability increases when moving from subannual to interannual timescales (Fig. 14b, c). This is most pronounced south of $25^{\circ} \mathrm{N}$ and at depths greater than a few hundred metres. At depths of around $2500 \mathrm{~m}$ where the maximum interannual MOC variability occurs the ratio can reach values in excess of 0.6, suggesting that a substantial fraction of the interannual MOC variability is of chaotic nature. North of about $30^{\circ} \mathrm{N}$ the ratio between chaotic and total MOC variability are comparable for subannual and interannual timescales. However, as shown in Fig. 12, the chaotic MOC variability is small on interannual timescales.
In the Indo-Pacific the ratio between chaotic and total MOC variability is lower than in the Atlantic (Fig. 14d, e, f). This is expected since the amplitude of the chaotic MOC variability is similar in both the Atlantic and the Indo-Pacific whereas the total MOC variability is higher in the IndoPacific than in the Atlantic (Fig. 6). As in the Atlantic low ratios are found at the Equator. This means that in the IndoPacific the large equatorial variability is also largely predictable from the surface forcing. Again this is consistent with the high correlations between the two model passes in the Indo-Pacific (Fig. 8).

The Antarctic circumpolar region is a region of high eddy activity, and Fig. 15a shows that this region coincides with the largest chaotic MOC variability away from the Equator. Between $40^{\circ} \mathrm{S}$ and $60^{\circ} \mathrm{S}$ the standard deviation of the total chaotic MOC variability can reach up to $3 \mathrm{~Sv}$. Compared with the total MOC variability for the Southern Ocean this leads to ratios of 0.4 to 0.6 (Fig. 15b), which are similar to the ones shown earlier for the South Atlantic (Fig. 12). As for the Indo-Pacific and Atlantic most of the chaotic MOC variability occurs on subannual timescales, with much less variability found on interannual timescales (not shown).

An underlying assumption of this study is that the amplitude of the chaotic MOC variability depends on the presence or absence of mesoscale ocean eddies. As illustrated in Fig. 13 the total chaotic MOC variability is smaller in $\mathrm{A} / \mathrm{B} 100$ than in $\mathrm{A} / \mathrm{B} 025$. This is further highlighted when looking at the ratio between chaotic and total MOC variability. For both the Atlantic and the Indo-Pacific the ratio between the chaotic and the total MOC variability is 0.1 or less for most latitudes and depths (Fig. 16a, b, d, e). This is much less than the fractions found for the eddy-permitting experiments A025 and B025. On interannual timescales the chaotic MOC variability accounts for fractions that are comparable to those seen for experiments A025 and B025. However, these high ratios are mostly found below $1000 \mathrm{~m}$ depth, i.e. below the depth where the largest MOC values tend to occur (Fig. 16c, f).

In order to get more insight into the nature of the chaotic MOC variability it is useful to look at Hovmöller diagrams of the MOC differences between experiments A025 and B025 (Fig. 17). On both subannual and interannual timescales the chaotic MOC variability exhibits meridional bands of coherence. In the Atlantic the largest subannual coherent features occur in the South Atlantic (Fig. 17a). The latitude band between $35^{\circ} \mathrm{S}$ and the Equator is characterised by coherent bands with alternative positive and negative values for the chaotic MOC variability. Such a large meridional coherence is not found in the North Atlantic, which instead is characterised by three bands of coherence: between the Equator and about $10^{\circ} \mathrm{N}$, from 10 to $25^{\circ} \mathrm{N}$, and from 25 to about $35^{\circ} \mathrm{N}$. North of $35^{\circ} \mathrm{N}$ there is an indication of northwardpropagating features. Hints of a northward-propagation in the North Atlantic are found between the two northernmost bands of coherence most likely reflecting anomalies 

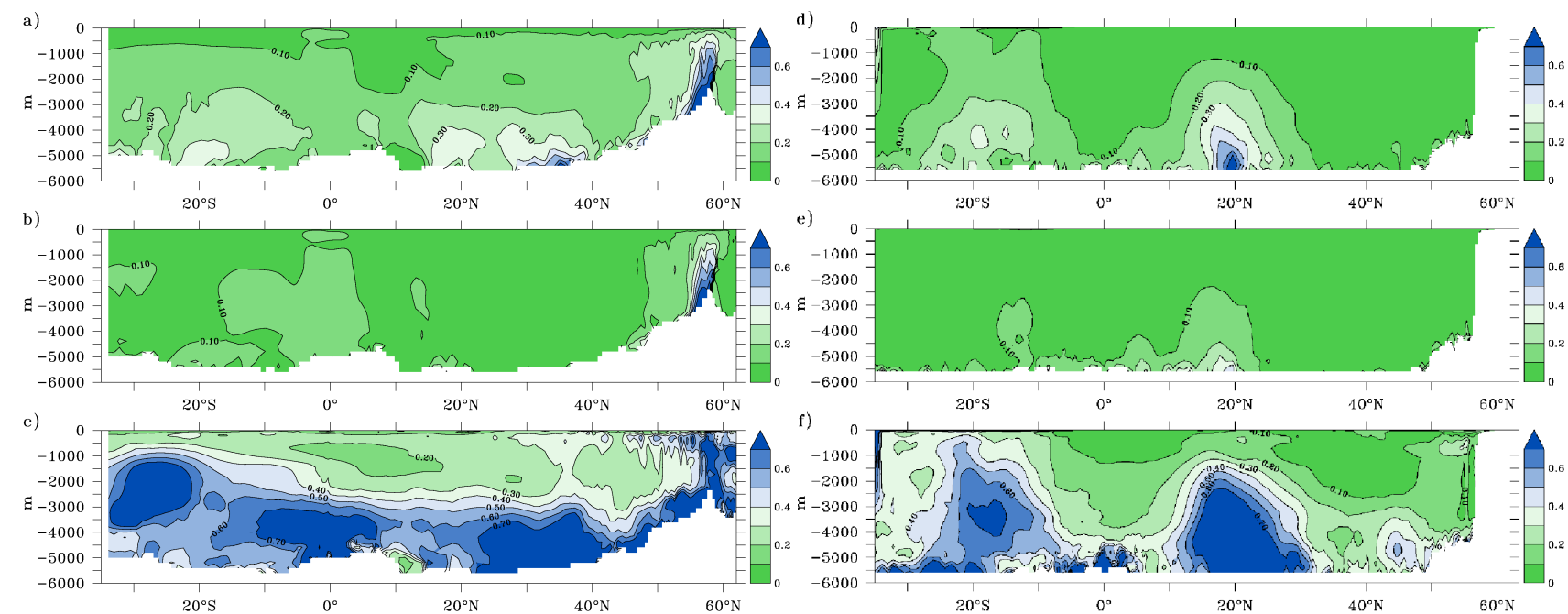

Fig. 16. Ratio between chaotic and total MOC variability for the Atlantic (a), (b), (c) and Indo-Pacific (d), (e), (f) in the non-eddy-permitting experiments A100 and B100. (a) Ratio for unfiltered MOC variability (based on 5-day averages). (b) Ratio for subannual MOC variability. (c) Ratio for interannual MOC variability. (d), (e), (f) as a,b,c but for Indo-Pacific. The contour interval is 0.1 .

propagating along the North Atlantic Current. The different bands of coherence in the North Atlantic are likely to reflect the more fractionated coastlines compared to the South Atlantic. Perturbations mediated through waves trapped along the continental margins have to follow longer, more tortuous pathways to propagate meridionally in the North Atlantic, which would explain the less coherent picture seen for the chaotic MOC fluctuations in the North Atlantic than in the South Atlantic.

On interannual timescales the values for the chaotic MOC variability are between -1.5 and $1.5 \mathrm{~Sv}$ (Fig. 17b). The equatorial "barrier" that characterised the subannual timescales appears much reduced and there are several instances of MOC fluctuations crossing the Equator. In the Northern Hemisphere there is still some indication of the three meridional bands of coherence $\left(10,25\right.$ and $\left.40^{\circ} \mathrm{N}\right)$ found for the subannual chaotic MOC variability. The amplitude and meridional extent of the interannual signals are similar to the MOC variability signals described by Biastoch et al. (2008), where the authors investigate the impact of mesoscale eddies in the Agulhas region on the variability of the Atlantic MOC. A feature common to both subannual and interannual timescales is the clear northern limit at about $40^{\circ} \mathrm{N}$. Beyond this latitude the amplitude of the chaotic MOC variability is much reduced and meridionally coherent features are no longer seen. This contrasts with the meridional coherence found when looking at anomalies of the MOC in experiment B025 after removing the Ekman contribution (Fig. 18). Here latitudinally coherent MOC bands are not confined south of $40^{\circ} \mathrm{N}$ but also characterise a latitude band between 40 and $60^{\circ} \mathrm{N}$. This is similar to the results documented by Bingham et al. (2007) for a coupled (HadCM3) and an oceanonly model (OCCAM). South of $40^{\circ} \mathrm{N}$ the MOC anomalies in B025 exhibit different coherent bands with meridional extents similar to those seen for the chaotic MOC.

The meridional coherence of the chaotic MOC variability in the Indo-Pacific is comparable to its Atlantic counterpart with coherent MOC bands characterising the latitudes south of about $40^{\circ} \mathrm{N}$ (Fig. 17c, d). The largest chaotic variability at $1000 \mathrm{~m}$ depth occurs at the Equator and around $10^{\circ} \mathrm{S}$, coinciding with the Indonesian Throughflow. Maximum chaotic variability around $10^{\circ} \mathrm{S}$ is found on subannual and interannual timescales and the amplitude of the chaotic MOC fluctuations can exceed $5 \mathrm{~Sv}$ (Fig. 17c, d). These fluctuations are likely linked to the variability of the Indonesian Throughflow, which contains a large chaotic (unforced) variability. However, as is indicated by the high correlations between the model passes 1 and 2 (Fig. 8) as well as the low ratios in Fig. 14, the chaotic variability around $10^{\circ} \mathrm{S}$ is small compared to the total MOC variability.

Away from the latitudes affected by the Indonesian Throughflow, the peak-to-peak values of the chaotic MOC variability and its meridional coherence are similar to what we find in the Atlantic. Values are typically a few Sv, which is consistent with the amplitudes found for the standard deviations of the chaotic MOC variability in the Indo-Pacific and Atlantic described earlier in this section (Fig. 14). As in the Atlantic, $40^{\circ} \mathrm{N}$ appears to be a barrier to the chaotic MOC signals in the Indo-Pacific and little chaotic MOC activity occurs further north. As before this is different from the behaviour found for the full MOC (with Ekman component removed), which shows a meridionally coherent variability between 40 and $60^{\circ} \mathrm{N}$ (Fig. 18c, d). 


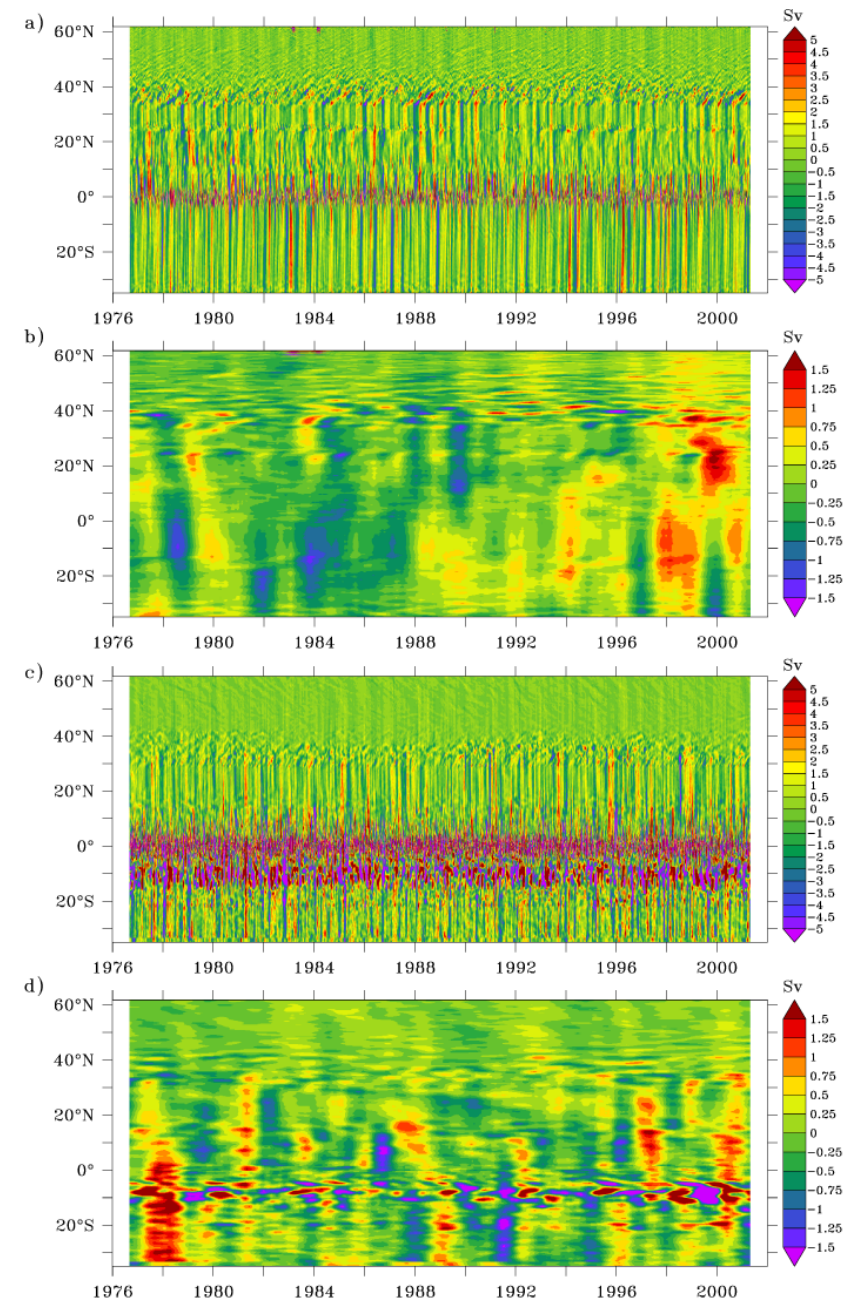

Fig. 17. Hovmöller diagram of the MOC difference between experiments A025 and B025 at $1000 \mathrm{~m}$ depth. (a), (b) Chaotic Atlantic MOC variability on subannual (a) and interannual (b) timescales. (c), (d) As panels (a), (b) but for Indo-Pacific.

\section{Discussion}

The main motivation for this study is to gain a better understanding of the impact that chaotic ocean processes, in particular mesoscale ocean eddies, could have on observations of the MOC. Recent observational programmes have dedicated much effort to observing the MOC. The results have shown that the MOC can exhibit large variability on short (subannual) timescales - a variability that is only partly understood. The question of how much of the observed signal reflects eddy (and baroclinic wave) activity cannot be addressed directly from the existing observations. A study by Wunsch (2008) suggested a possible eddy imprint that could exceed the full MOC signal observed at $26.5^{\circ} \mathrm{N}$. A thorough study by Kanzow et al. (2009) demonstrated that the imprint of eddies on the MOC is much smaller. However, the obser-
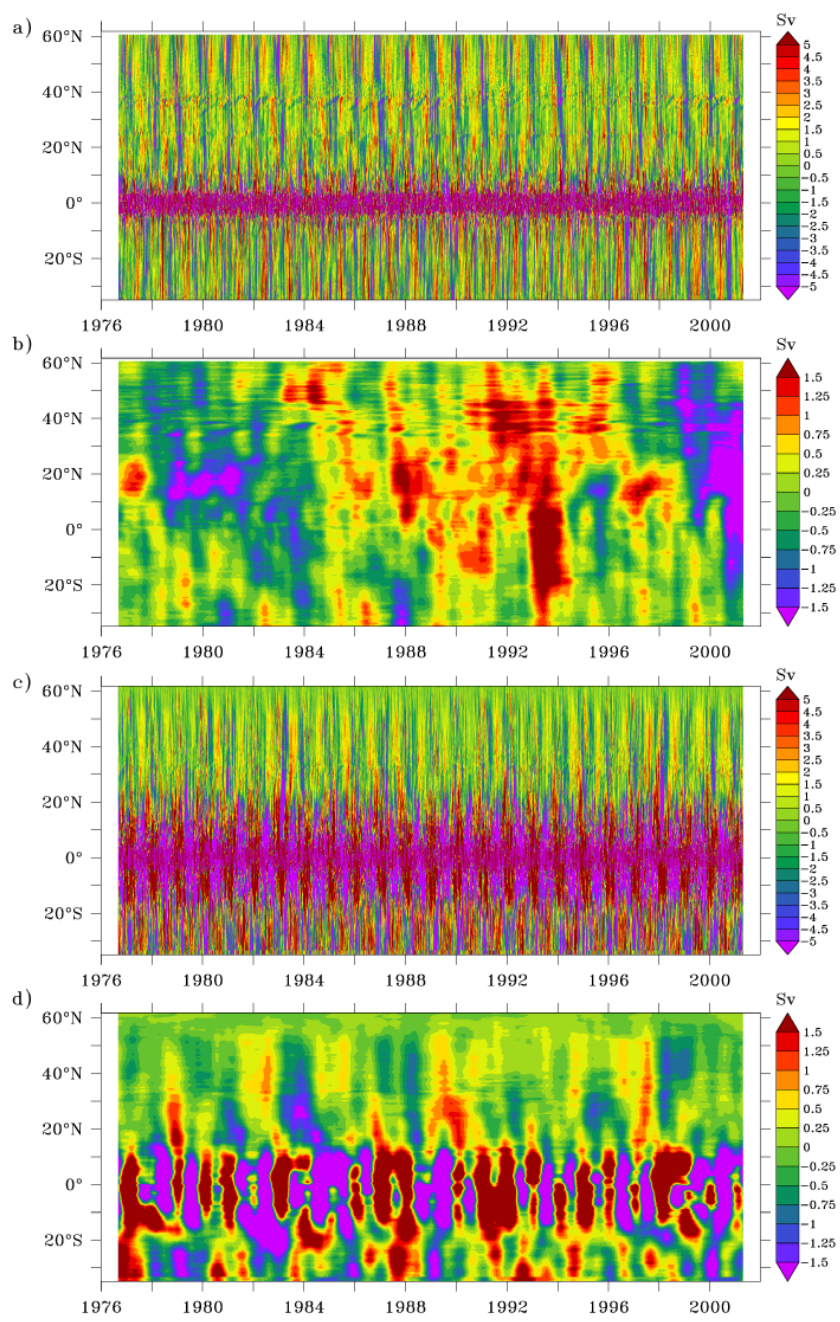

Fig. 18. Hovmöller diagram for MOC-Ekman transport at $1000 \mathrm{~m}$ depth for experiment B025. (a), (b) Atlantic MOC on subannual (a) and interannual (b) timescales. (c), (d) As (a), (b) for Indo-Pacific.

vational data currently available do not allow a quantification of the chaotic MOC variability.

Our results suggest that the chaotic MOC variability accounts for a few $\mathrm{Sv}$ of the total MOC variability. When the depth of the maximum MOC is considered (typically at about $1000 \mathrm{~m}$ depth), about 20 to $30 \%$ (Atlantic), respectively $10 \%$ (Indo-Pacific), of the MOC variability is chaotic. For the eddy-permitting model our results suggest that 70 to $80 \%$ (Atlantic), respectively $90 \%$ (Indo-Pacific), of the MOC variability can directly be attributed to the surface forcing (winds, heat and fresh water fluxes). The fact that on sub- to interannual timescales the MOC variability mainly reflects the surface forcing is illustrated by the high correlations (Fig. 8) between the numerical experiments A025 and B025 (A100, B100). The main implication is that on sub- to interannual timescales the MOC variability is largely predictable from the surface forcing conditions. Despite be- 


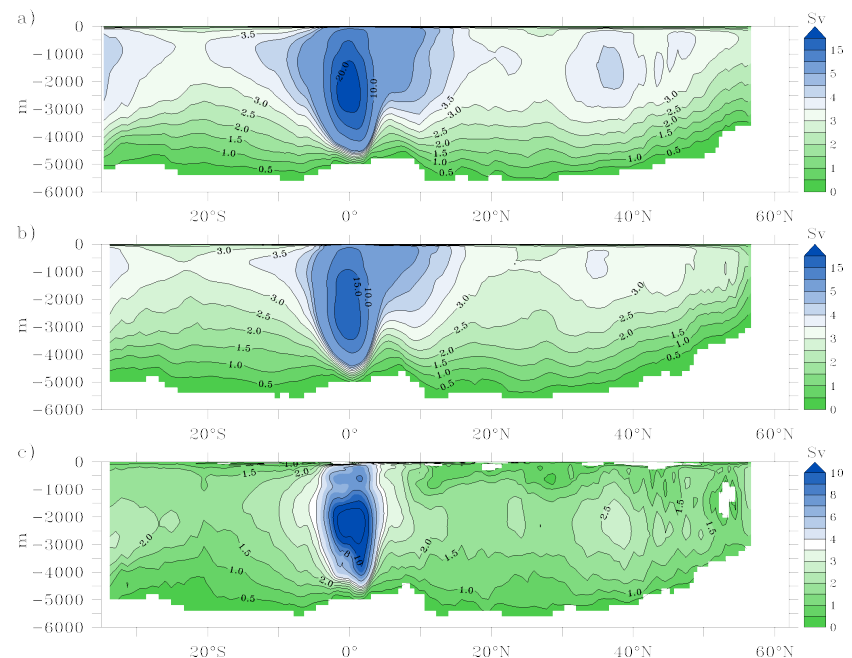

Fig. 19. Standard deviations of the Atlantic MOC in the $1 / 4^{\circ}$ (a) and $1^{\circ}$ (b) versions of the model (c). The standard deviation of the additional variability occurring in the $1 / 4^{\circ}$ model is shown in the bottom panel. It is calculated according to $\sqrt{\text { variance }_{\mathrm{B} 025}-\text { variance }_{\mathrm{B} 100}}$.

ing of a sizeable amplitude the chaotic (non-deterministic) MOC variability is too small to affect the overall MOC variability. This also means that the variability of the MOC that has been observed since 2004 at $26.5^{\circ} \mathrm{N}$ in the North Atlantic is unlikely to mainly reflect processes such as mesoscale ocean eddies or baroclinic waves that are not directly linked to the surface forcing. At the same time the high correlations between the model passes 1 and 2 also suggest that a good knowledge of the surface forcing might be enough to estimate the MOC not just at the surface but even down to greater depths. To obtain the correlation patterns shown in Fig. 8 one does not need the full 25 years (1976 to 2001) of model data, but the correlation patterns look almost identical if only half the data were used (e.g. 1976 to 1988, not shown). This means that one could just build a simple linear regression model based on the relationship between the surface forcing and the MOC relationship for the years 1976 to 1988 that can then be used to predict the MOC for the years 1989 to 2001 from the surface forcing alone. Our results suggest that such a simple model would do a good job not just for the obvious Ekman component in the surface layers but also down to depths of at least $1000 \mathrm{~m}$, which typically coincide with the depth at which the MOC reaches its maximum value. Of course based on our results we can only comment on subto interannual timescales. To assess whether the relationship between the variability in the surface forcing and the MOC also holds on decadal and longer timescales would require longer simulations and cannot be answered in this study. It is also clear that a regression model as described above would not be capable of detecting a regime change (e.g. when fresh
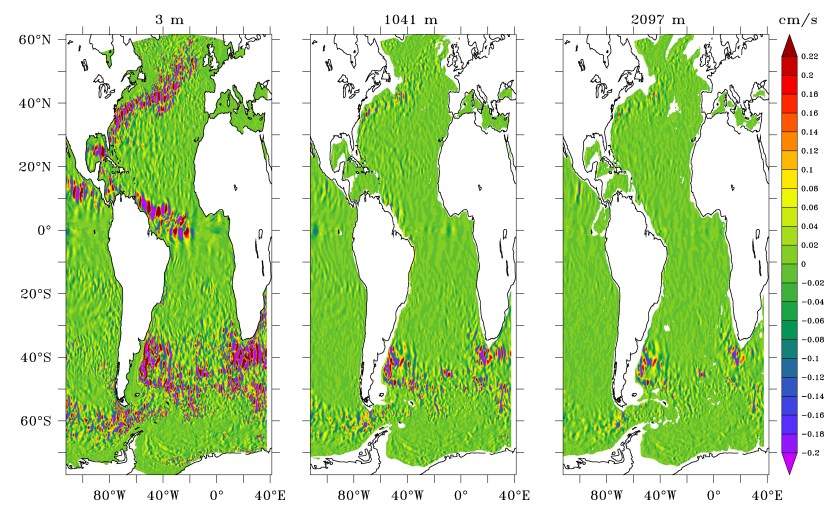

Fig. 20. Different depth ranges of mesoscale features in the North and South Atlantic. Difference between A025 and B025 for meridional velocities.

water forcing exceeds a critical threshold, leading to a major reorganisation of the MOC).

Despite the high correlations between the forcing and the MOC our results also show regions where the chaotic variability is a sizeable component of the total MOC variability. This is most pronounced in the South Atlantic. On interannual and to a lesser extent also on subannual timescales there is a gradual decrease of the correlations between passes 1 and 2 when moving towards the southern limit of the Atlantic domain. This is most pronounced below $2000 \mathrm{~m}$ depth. Whereas low correlations (and high ratios between chaotic and total MOC variability) are typically found in the bottom layers (where MOC values and variability are low), the South Atlantic is characterised by lower correlations at depths between 2000 and $3000 \mathrm{~m}$ depth where there is still a substantial MOC variability (Figs. 6 and 8). On interannual timescales the correlation between the surface forcing and the MOC is less than 0.7 over a large part of the water column in the South Atlantic; i.e. more than $50 \%$ of the interannual variability cannot be explained by the surface forcing. This means that a substantial fraction of the variability of the (southward) meridional transports compensating the surface MOC branch is affected by internal processes such as mesoscale eddies and baroclinic waves. So why is it that the chaotic MOC variability is more pronounced in the South Atlantic than in the North Atlantic? As mentioned earlier the largest differences between the two model passes occur because of a decorrelation of the mesoscale ocean eddy field (Fig. 2). However, why would mesoscale eddies have a larger imprint on the MOC in the South Atlantic than in the North Atlantic? Mesoscale ocean eddies are formed in both hemispheres, with the Gulf Stream region as well as the southern tip of Africa or the area of the Zapiola anticyclone all showing lively eddy activity. A plausible reason why the imprint of chaotic processes in NEMO is larger in the South Atlantic than in the North Atlantic could be linked to the different depths down to which pronounced mesoscale activity 


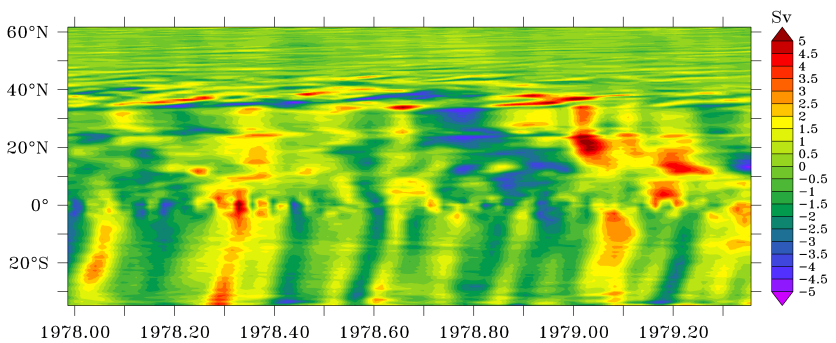

Fig. 21. Propagation of chaotic MOC anomaly fluctuations in the Atlantic at $1000 \mathrm{~m}$ depth (eddy-permitting case).

occurs in our simulations (Fig. 20). When the surface layers are considered, both the North and South Atlantic seem to have similar mesoscale activities. However, this picture changes when moving deeper into the water column. Below depths of a few hundred metres the mesoscale activity is larger in the South Atlantic. From about $1000 \mathrm{~m}$ onwards there is only little mesoscale activity in the North Atlantic, whereas the South Atlantic regions show mesoscale features down to depths of several thousand metres (Fig. 20). Note that, qualitatively, it makes no difference whether the meridional velocities in Fig. 20 are plotted from either experiment A025, B025 or from their difference. The low correlations between mesoscale features in both model passes mean that the inferred regions of high mesoscale variability are always the same. An interesting feature is that the eddy variability found at greater depths in the Zapiola region extends almost to the continental margin, therefore increasing the potential of these mesoscale features to directly affect the basin-wide density gradient and therefore basin-wide meridional transports (Hirschi and Marotzke, 2007; Hirschi et al., 2003).

What also emerges from Fig. 20 is that in the South Atlantic the regions of highest ocean eddy activity are found south of the southern limit where the Atlantic MOC can be computed (i.e. the southern tip of Africa). This means that signals have to propagate northward from the regions of high mesoscale activity. This is most likely to happen as boundary-trapped Kelvin-like waves along the east coast of South America. Such waves have been shown to rapidly transfer perturbations from high to low latitudes (e.g. Kawase, 1987; Hirschi and Stocker, 2002; ; Roussenov et al., 2008; Blaker et al., 2006), and it has been suggested that ocean mesoscale eddies can trigger boundary-trapped waves (Kanzow et al., 2009). Looking at the chaotic MOC signals in the Atlantic at a high temporal resolution reveals that indeed the chaotic MOC fluctuations are propagating meridionally (Fig. 21). The coherent MOC features between about $35^{\circ} \mathrm{S}$ and the Equator propagate from the southern limit of the Atlantic domain to the Equator in about one month. This corresponds to a propagation speed of slightly more than $1 \mathrm{~m} \mathrm{~s}^{-1}$, which is close to the phase speed expected for baroclinic Kelvin waves. Compared to most other east coasts on the globe the South Atlantic east coast is smooth with an al- most north-south orientation. This allows a fast meridional propagation of perturbations.

It is worth noting that the increase in chaotic MOC variability found for the eddy-permitting model compared to the non-eddying case is smaller than the overall increase in MOC variability obtained when increasing the model resolution from 1 to $1 / 4^{\circ}$. This is illustrated for the Atlantic in Fig. 19. The overall MOC variability is about $20 \%$ higher in B025 than in B100. This increase in MOC variability between B025 and B100 is larger than the chaotic MOC variability found in the Atlantic (Fig. 12a). This means that when we increase the model resolution from 1 to $1 / 4^{\circ}$ not all the additional variability we see for the $1 / 4^{\circ}$ version of the model has to be unpredictable. Some of it will be readily predictable from the forcing, as the overall MOC variability not just increases because of chaotic processes such as ocean mesoscale eddies but can also increase as ocean processes such as wave processes or western boundary currents are better resolved. Additionally, the viscosity is lower in experiments A025/B025 than in A100/B100, which favours a higher (predictable) variability.

Further insight into the nature of the chaotic MOC variability could be gained by decomposing the MOC into its constituents (Ekman, thermal wind (i.e. geostrophic), and barotropic components, [e.g. Lee and Marotzke, 1998; Hirschi and Marotzke, 2007; Blaker et al., 2012) or by considering the MOC in density coordinates. The correlations between the MOC in experiments A025 and B025 show that correlations are very high $(>0.9)$ for all latitudes in the Atlantic and the Indo-Pacific in the surface layers (Figs. 8 and 9) . This is a strong indication that Ekman transports are almost identical in the two model passes. Therefore, differences in the MOC in the twin simulations must have their origin in the thermal wind and barotropic components. Preliminary results suggest that the chaotic variability found in the barotropic and geostrophic MOC components exceeds that found for the total MOC. This is not unexpected given that there is compensation between the barotropic and geostrophic MOC components (Kanzow et al., 2007).

Another interesting and perhaps counterintuitive result of our analysis is that the chaotic MOC variability is not confined to timescales that are associated with the lifetime of mesoscale ocean eddies. Our results suggest that interannual chaotic MOC variability of similar amplitude occur for both the eddy-permitting and the non-eddy-permitting resolutions. However, at $1000 \mathrm{~m}$ where the maximum MOC tends to occur, the fraction of interannual MOC variability is typically somewhat larger in the eddy-permitting than in the non-eddying model (Figs. 14 and 16), therefore suggesting that the presence of ocean mesoscale eddies may affect the chaotic MOC variability on interannual timescales. Studies have shown that the energy from mesoscale eddies does cascade to larger-length scales (and the large-scale flow can affect the eddy field, i.e. forward and backward energy cascades, e.g. Scott and Wang, 2005; Scott and Ar- 
bic, 2007). The presence of a chaotic MOC variability on longer timescales would also be consistent with the results of a recent numerical study where the authors investigated the variability of sea surface height (SSH) in two NEMO $1 / 4^{\circ}$ simulations forced with either climatological or interannual forcing (Penduff et al., 2011). Despite the absence of interannual forcing in the climatological simulation, the authors found that the amplitude of interannual SSH variability in the climatological simulation was between 40 and $80 \%$ of the SSH variability found for the simulation using interannual atmospheric forcing. This suggests that even on interannual timescales a large fraction of the intrinsic SSH variability is not directly forced by the atmosphere but results from chaotic (intrinsic) ocean variability. Our results indicate that this may not translate into a large chaotic interannual MOC variability. The small dependence on model resolution found in our study suggests that the chaotic interannual MOC variability is not necessarily eddy-driven but may result from different phases of oceanic waves (e.g. (topographic) Rossby waves, Kelvin waves, etc.) between the different model passes as well as from model drift in water mass properties. Wave processes are present in both the eddypermitting and non-eddy-permitting versions of the model. In experiments A100 and B100 differences in wave phases between continental margins are the likely cause of the interannual chaotic MOC variability. For experiments A025 and B025 it is not yet clear to what extent the interannual chaotic MOC variability is due to differences in waves phases or to ocean mesoscale eddies. We note that water mass drift can also contribute to changes of the MOC. However, such changes tend to be in the shape of gradual long-term trends rather than interannual fluctuations. However, by changing the background state of the ocean, water mass drift modifies the initial conditions experienced between the model passes. Therefore, water mass drift in the model can indirectly affect MOC variability on shorter timescales as it contributes to the different ocean background state which leads to different timings for mesoscale eddy formation and wave phases.

We use the Eulerian overturning streamfunction to diagnose the MOC and do not consider possible effects of the eddy streamfunction (e.g. Lee and Coward, 2003) in experiments A025/B025 and of the bolus velocity in experiments A100/B100. In the Southern Ocean in particular the eddy streamfunction (A025/B025) and bolus velocities (A100/B100) can compensate changes in the Eulerian streamfunction. The residual streamfunction (sum of Eulerian and eddy streamfunctions) can therefore differ substantially from the Eulerian streamfunction, and the fraction of "chaotic" variability in the residual streamfunction may differ from the numbers reported here. However, the Eulerian streamfunction is widely used in the community to diagnose the MOC in ocean models, which is why we concentrated on this quantity in the present study. In addition to the residual streamfunction it would also be instructive to further study the nature of the chaotic MOC variability by looking at the different MOC components (e.g. western boundary transports, geostrophic interior transport and barotropic transport) or to consider the MOC in density coordinates. However, these aspects are beyond the scope of the present paper and are left for future studies.

The estimates of the chaotic MOC variability obtained in this study have to be regarded as a lower limit. The eddying model that we use is eddy-permitting but not eddy-resolving. Therefore, the impact of eddies on the ocean variability is likely to be underestimated. Preliminary tests performed with a $1 / 12^{\circ}$ version of NEMO suggest that the total MOC variability is about $20 \%$ higher than in the $1 / 4^{\circ}$ version used here, hinting to the possibility of a larger eddy imprint on the MOC. Our results also only provide an indication of the amplitude of the chaotic MOC variability originating in the ocean provided that the atmospheric forcing is known. In the real world (as well as in coupled models where the ocean is eddying, e.g. CM2.5/2.6, HadGEM3-H (Hewitt et al., 2010; Delworth et al., 2012)) mesoscale ocean eddies can feed back onto the atmosphere. Therefore two coupled model simulations starting from identical atmospheric conditions as well as (apart from the ocean eddy field) from the same ocean will eventually experience different atmospheric conditions due to the different eddy-fields. After a certain number of months/years one model run may find itself in a prolonged positive NAO phase, whereas for the same dates the other simulation is in a negative NAO state. Such differences in the atmospheric conditions would obviously feed back onto the ocean, and as a consequence the chaotic MOC variability of a coupled ocean-atmosphere system will be larger than the numbers reported in this study. The presence of mesoscale ocean eddies adds variability to the climate system with possible consequences for its predictability. More work is still required to gain a better understanding of possible impacts of mesoscale ocean eddies on climate variability/predictability if we want to make best use of the latest generation of coupled climate model using eddy-permitting (and soon eddyresolving) ocean components that are currently being developed by research centres around the world.

\section{Conclusions}

We have studied the chaotic and forced MOC variability by comparing eddy-permitting and non-eddy-permitting twin experiments which start from different initial conditions but which are forced with the same atmospheric forcing. We have found the following :

- The MOC variability in the twin experiments is highly correlated on sub- to interannual timescales. High correlations are not confined to the obvious Ekman layer at the surface but reach down to several $\mathrm{km}$. To a large extent the MOC directly reflects the atmospheric forcing on sub- to interannual timescales. 
- In the presence of mesoscale ocean eddies the chaotic Atlantic MOC variability accounts for 20 to $30 \%$ (Atlantic) and 10 to $20 \%$ (Indo-Pacific) of the total MOC where the maximum MOC occurs (typically at a depth of around $1000 \mathrm{~m}$ ). In the non-eddying case the chaotic MOC variability generally accounts for less than $10 \%$ of the total MOC variability.

- The largest chaotic MOC variability occurs at the Equator with a standard deviation of $3 \mathrm{~Sv}$ (Atlantic) and $8 \mathrm{~Sv}$ (Indo-Pacific). However, this is only a small fraction $(<10 \%)$ of the very large equatorial MOC variability (standard deviations of 23 and $60 \mathrm{~Sv}$ in the Atlantic and Indo-Pacific, respectively). Away from the Equator the chaotic MOC variability is typically between 0.8 and $1.5 \mathrm{~Sv}$ and is similar in both Atlantic and Indo-Pacific

- The chaotic MOC variability exhibits meridional coherence. This is most pronounced in the South Atlantic where chaotic MOC anomalies are often coherent from about $35^{\circ} \mathrm{S}$ to the Equator. From the eddy-rich region in the South Atlantic chaotic MOC anomalies propagate equatorwards with a speed comparable to that expected for a baroclinic Kelvin wave.

- Our results support earlier findings that the MOC observations at $26.5^{\circ} \mathrm{N}$ are unlikely to be strongly affected by eddy-induced variability. However, our estimate of chaotic MOC variability has to be regarded as a lower limit given that the model we used is eddy-permitting and not eddy-resolving.

Acknowledgements. This work was supported by the RAPIDWATCH project VALOR (NE/G007772/1), the NERC project MESO-CLIP (NE/K005928/1) and was also part of the DRAKKAR project. We enjoyed discussions with Thierry Penduff and Florian Sévellec. We also thank Balu Nadiga and an anonymous reviewer for their constructive comments that helped to improve the paper.

Edited by: M. Hecht

\section{References}

Antonov, J., Levitus, S., Boyer, T. P., Conkright, M., O’Brien, T., and Stephens, C.: Temperature of the Atlantic/Pacific/Indian Ocean, Vols 1-3, World Ocean Atlas 1998, Technical report, NOAA Atlas NESDIS 27, 166 pp., 1998.

Biastoch, A., Böning, C. W., and Lutjeharms, J. R. E.: Agulhas leakage dynamics affects decadal variability in Atlantic overturning circulation, Nature, 456, 489-492, 2008.

Bingham, R. J., Hughes, C. W., Roussenov, V., and Williams, R. G.: Meridional coherence of the North Atlantic meridional overturning circulation, Geophys. Res. Let., 34, L23606, 1-6, 2007.
Blaker, A. T., Sinha, B., Ivchenko, V. O., Wells, N. C., and Zalesny, V. B.: Identifying the roles of the ocean and atmosphere in creating a rapid equatorial response to a Southern Ocean anomaly, Geophys. Res. Lett., 33, L06720, doi:10.1029/2005GL025474, 2006.

Blaker, A. T., Hirschi, J. J.-M., Sinha, B., de Cuevas, B., Alderson, S., Coward, A., and Madec, G.: Large near-inertial oscillations of the Atlantic meridional overturning circulation, Ocean Modell., 42, 50-56, 2012.

Bradley, R. S.: Quaternary Paleoclimatology: Methods od Paleoclimatic Reconstruction, Allen and Unwin, Boston, 1985.

Brodeau, L., Barnier, B., Penduff, T., Treguier, A.-M., and Gulev, S.: An ERA 40 based atmospheric forcing for global ocean circulation models, Ocean Modell., 31, 88-104, 2010.

Collins, M. and Sinha, B.: Predictability of decadal variations in the thermohaline circulation and climate, Geophys. Res. Lett., 30, 391-394, doi:10.1029/2002GL016504, 2003.

Cunningham, S. A., Kanzow, T., Rayner, D., Baringer, M. O., Johns, W. E., Marotzke, J., Longworth, H. R., Grant, E. M., Hirschi, J. J.-M., Beal, L. M., Meinen, C. S., and Bryden, H. L.: Temporal variability of the Atlantic Meridional Overturning Circulation at $26^{\circ}$ N., Science, 317, 935-938, doi:10.1126/science.1141304, 2007.

Czaja, A. and Frankignoul, C.: Observed Impact of Atlantic SST Anomalies on the North Atlantic Oscillation, J. Climate, 15, 606-623, 2002.

Delworth, T. L., Rosati, A., Anderson, W., Adcroft, A. J., Balaji, V., Benson, R., Dixon, K., Griffies, S. M., Lee, H.-C., Paconowski, R. C., Vecchi, G. A., Wittenberg, A. T., Zeng, F., and Zhang, R.: Simulated climate change in the GFDL CM2.5 high-resolution coupled climate model, J. Climate, 25, 2755-2781, 2012.

Donners, J., Drijfhout, S. S., and Coward, A. C.: Impact of cooling on the water mass exchange of the Agulhas rings in a high resolution ocean model, Geophys. Res. Lett., 31, doi:10.1029/2004GL020644, 2004.

Drevillon, M., Bourdalle-Badie, R., Derval, C., Drillet, Y., Lellouche, J.-M., Remy, E., Tranchant, B., Benkiran, M., Greiner, E., Guinehut, S., Verbrugge, N., Garric, G., Testut, C.-E., Laborie, M., Nouel, L., Bahurel, P., Bricaud, C., Crosnier, L., Dombrowsky, E., Durand, E., Ferry, N., Hernandez, F., Galloudec, O. L., Messal, F., and Parent, L.: The godae/mercatorocean global ocean forecasting system: results, applications and prospects, J. Operat. Oceanogr., 1, 51-57, 2008.

Hawkins, E. and Sutton, R.: Decadal Predictability of the Atlantic Ocean in a Coupled GCM: Forecast Skill and Optimal Perturbations Using Linear Inverse Modelling, J. Climate, 22, 39603978, 2009.

Hewitt, H. T., Copsey, D., Culverwell, I. D., Harris, C. M., Hill, R. S. R., Keen, A. B., McLaren, A. J., and Hunke, E. C.: Design and implementation of the infrastructure of HadGEM3: the nextgeneration Met Office climate modelling system, Geosci. Model Dev., 4, 223-253, doi:10.5194/gmd-4-223-2011, 2011.

Hirschi, J. and Marotzke, J.: Reconstructing the meridional overturning circulation from boundary densities and the zonal wind stress, J. Phys. Oceanogr., 37, 743-763, 2007.

Hirschi, J. and Stocker, T. F.: Rapid changes of the oceanic circulation in a hierarchy of ocean models, Tellus A, 54, 273-287, 2002. 
Hirschi, J., Baehr, J., Marotzke, J., Stark, J., Cunningham, S., and Beismann, J.-O.: A monitoring design for the Atlantic meridional overturning, Geophys. Res. Lett., 30, 1413-1416, 2003.

Hirschi, J. J.-M., Killworth, P. D., and Blundell, J. R.: Subannual, seasonal and interannual variability of the North Atlantic meridional overturning circulation, J. Phys. Oceanogr., 37, 1246-1265, 2007.

Hirschi, J. J.-M., Killworth, P. D., and Blundell, J. R.: Sea surface height signals as indicators for oceanic meridional mass transports, J. Phys. Oceanogr., 39, 581-601, doi:10.1175/2008JPO3923.1, 2009.

Imbrie, J., Boyle, E. A., Clemens, S. C., Duffy, A., Howard, W. R., Kukla, G., Kutzbach, J., Martinson, D. G., McIntyre, A., Mix, A. C., Molfino, B., Morley, J. J., Peterson, L. C., Pisias, N. G., Prell, W. L., Raymo, M. E., Shackleton, N. J., and Toggweiler, J. R.: On the structure and origin of major glaciation cycles, 1 . linear responses to Milankovitch forcing, Paleoceanogr., 7, 701738, 1992.

Jayne, S. R. and Marotzke, J.: The Dynamics of Ocean Heat Transport Variability, Rev. Geophys., 39, 385-411, 2001.

Johnson, H. L. and Marshall, D. P.: A theory of the surface Atlantic response to thermohaline variability, J. Phys. Oceanogr., 13, 1121-1132, 2002.

Kanzow, T., Johnson, H. L., Marshall, D., Cunningham, S. A., Hirschi, J. J.-M., Mujahid, A., Bryden, H. L., and Johns, W. E.: Basin-wide integrated volume transports in an eddy-filled ocean, J. Phys. Oceanogr., 39, 3091-3110, 2009.

Kanzow, T., Cunningham, S. A., Johns, W. E., Hirschi, J. J.-M., Marotzke, J., Baringer, M. O., Meinen, C., Chidichimo, M.-P., Atkinson, C., Beal, L. M., Bryden, H. L., and Collins, J.: On the seasonal variability of the Atlantic meridional overturning circulation at $26.5^{\circ} \mathrm{N}, \mathrm{J}$. Climate, 317, 938-941, 2010.

Kawase, M.: Establishment of deep ocean circulation driven by deep water production, J. Phys. Oceanogr., 17, 2294-2317, 1987.

Large, W. and Yeager, S.: Diurnal to decadal global forcing for ocean and sea-ice models: the data sets and flux climatologies, Technical report, CGD Division of the National Centre for Atmospheric Research, 2004.

Lee, T. and Marotzke, J.: Seasonal Cycles of Meridional Overturning and Heat Transport of the Indian Ocean, J. Phys. Oceanogr., 28, 923-943, 1998.

Lee, M.-M. and Coward, A.: Eddy mass transport for the southern ocean in an 925 eddy-permitting global ocean model, Oc. Modell., 5, 249-266, 2003.

Madec, G.: Nemo ocean engine, Technical report, Institut PierreSimon Laplace (IPSL), France, (Note du Pole de Modélisation, 27), 300 pp., 2008.

Martin, M. J., Hines, A., and Bell, M. J.: Data assimilation in the FOAM operational short-range ocean forecasting system: a description of the scheme and its impact, Quart. J. Roy. Met. Soc., 133, 981-995, 2007.
McPhaden, M. J.: Genesis and Evolution of the 1997-1998 El Niño, Science, 283, 950-954, doi:10.1126/science.283.5404.950, 1999.

Penduff, T., Juza, M., Brodeau, L., Smith, G. C., Barnier, B., Molines, J.-M., Treguier, A.-M., and Madec, G.: Impact of global ocean model resolution on sea-level variability with emphasis on interannual time scales, Ocean Sci., 6, 269-284, doi:10.5194/os6-269-2010, 2010.

Penduff, T., Juza, M., Dewar, W. K., Barnier, B., Zika, J., Treguier, A.-M., Molines, J.-M., and Audiffren, N.: Sea-level expression of intrinsic and forced ocean variabilities at interannual timescales, J. Climate, 24, 5652-5670, 2011.

Rayner, D., Hirschi, J. J.-M., Kanzow, T., Johns, W. E., Wright, P. G., Frajka-Williams, E., Bryden, H. L., Meinen, C. S., Baringer, M. O., Marotzke, J., Beal, L. M., and Cunningham, S. A.: Monitoring the Atlantic Meridional Overturning Circulation, Deep Sea Res., 58, 1744-1753, 2011.

Roussenov, V. M., Williams, R. G., Hughes, C. W., and Bingham, R.: Boundary wave communication of bottom pressure and overturning changes for the North Atlantic, J. Geophys. Res., 113, C08042, doi:10.1029/2007JC004501, 2008.

Scott, R. and Arbic, B.: Spectral Energy Fluxes in Geostrophic Turbulence: Implications for Ocean Energetics, J. Phys. Oceanogr., 37, 673-688, 2007.

Scott, R. and Wang, F.: Direct Evidence of an Oceanic Inverse Kinetic Energy Cascade from Satellite Altimetry, J. Phys. Oceanogr., 35, 1650-1666, 2005.

Sévellec, F., Huck, T., Ben Jelloul, M., and Grima, N.: Optimal Surface Salinity Perturbations of the Meridional Overturning and Heat Transport in a Global Ocean General Circulation Model, J. Phys. Oceanogr., 38, 2739-2754, doi:10.1175/2008JPO3875.1, 2008.

Stammer, D.: Global Characteristics of Ocean Variability Estimated from Regional TOPOX/POSEIDON Altimeter Measurements, J. Phys. Oceanogr., 27, 1743-1769, 1997.

Stommel, H.: Thermohaline convection with two stable regimes of flow, Tellus, 13, 224-241, 1961.

Williams, R. G., Wilson, C., and Hughes, C. W.: Ocean and Atmosphere Storm Tracks: The role of Eddy Vorticity Forcing, J. Phys. Oceanogr., 37, 2267-2289, 2007.

Wunsch, C.: Mass and volume transport variability in an eddy-filled ocean, Nat. Geosci., 1, 165-168, 2008.

Zanna, L. and Tziperman, E.: Non-normal Amplification of the Thermohaline Circulation, J. Phys. Oceanogr., 35, 1593-1605, 2005. 